\title{
Límites y contenido esencial de los derechos (un marco conceptual problemático) $)^{* * * * * *}$
}

\section{Limits and essential content of rights (A problematic conceptual framework)}

\begin{abstract}
Quello che le corti costituzionali chiamano temerariamente "contenuto essenziale" dei diritti è esso stesso un'entità controversa, essendo precisamente il luogo in cui convergono i disaccordi sui diritti.
\end{abstract}

Anna Pintore, Democrazia e diritti. Sette studi analitici

En la medida en que se trata de la vida real, sería mejor -pienso- distinguir entre verdad y justicia, por una parte, y el valor moral de la selección de un método para alcanzar la verdad, y la justicia, por otra. Y el derecho positivo y los procesos jurídicos son, indudablemente, asuntos de la vida real.

Letizia Gianformaggio, La noción de procedimiento en la teoría de la argumentación jurídica

RESUMEN

Las así llamadas teorías de los límites de los derechos, en sus dos variantes -teoría de los límites externos y teoría de los límites internos-, en sus formulaciones usuales, así como las así llamadas teorías del contenido esencial de los derechos fundamentales -teoría absoluta, teoría relativa y teoría de no restricción-, aunque son ampliamente compartidas y citadas, presentan varios problemas. Vistas con ojo analítico, estas teorías no ofrecen un marco

Profesor de Filosofía del Derecho del Colegio de Jurisprudencia de la Universidad San Francisco de Quito (Quito, Ecuador). Miembro fundador de la Sociedad Ecuatoriana de Filosofía del Derecho (sefiDe); miembro correspondiente del Istituto Tarello per la Filosofia del Diritto. Contacto: mmaldonadom@usfq.edu.ec orCID: 0000-0002-2869-1339.

** Recibido el 9 de julio de 2019, aprobado el 12 de junio de 2020.

Para citar el artículo: MALdonado MuÑoz, M. Límites y contenido esencial de los derechos (un marco conceptual problemático). En Revista Derecho del Estado, Universidad Externado de Colombia. N. ${ }^{\circ} 47$, septiembre-diciembre de 2020, 79-112.

DOI: https://doi.org/10.18601/01229893.n47.03

*** $\quad$ Sebastián Reyes y Pedro Caminos leyeron y comentaron una versión previa de este trabajo. Estoy muy agradecido por sus oportunas sugerencias.

En los casos en que no se cita directamente la versión castellana, la traducción es del autor del presente trabajo. 
conceptual estable o que sirva para reconstruir la práctica efectiva en los casos iusfundamentales.

PALABRAS CLAVE

Derechos fundamentales, límites de los derechos, contenido esencial de los derechos, jerarquías axiológicas, realismo jurídico.

\section{ABSTRACT}

The so-called theories of the limits of fundamental rights, in their two variants - theory of external limits and theory of internal limits - in their usual formulations, as well as the so-called theories of the essential content of fundamental rights - absolute theory, relative theory, and non-restriction theory - although they are widely shared and cited, they present several problems. From an analytical point of view, these theories do not offer a stable conceptual framework or one that serves to reconstruct effective practice in fundamental rights cases.

\section{KEYWORDS}

Fundamental rights, Limits of rights, Essential content of rights, Axiological hierarchies, Legal realism.

\section{SUMARIO}

1. Planteamiento general. 2. Teorías de los límites de los derechos. 2.1. Teoría de los límites externos. 2.2. Teoría de los límites internos. 3. Teorías del contenido esencial. 3.1. Teoría absoluta del contenido esencial. 3.2. Teoría relativa del contenido esencial. 3.3. Teoría de la inalterabilidad del contenido de los derechos. 4. Algunas observaciones. 5. Derechos fundamentales, casos iusfundamentales y jerarquías. 6. Y, sin embargo... Referencias.

\section{PLANTEAMIENTO GENERAL}

Las teorías (o doctrinas ${ }^{1}$, si se quiere) de los "límites" y del "contenido esencial" de los derechos suelen hacer parte de la cultura mainstream en el estudio de los derechos fundamentales. Se trata, quizás, de las teorías más difundidas en el ámbito "continental", una especie de lingua franca con la

1 De aquí en más, esta diferencia (aquella entre teoría y doctrina, teoría e ideología) solo será ulteriormente discutida, al menos de modo tangencial, en el punto 4. En todo caso, al respecto, véase GuAstini, R. La sintaxis del derecho. Madrid: Marcial Pons, 2016. 
que juristas y jueces se comunican e incluso resuelven (o pretenden resolver) problemas respecto de los derechos fundamentales. Esto, ya que se supone que ellas apuntan, en términos generales, a brindar un marco conceptual que permitiría no solo entender qué son, sino también qué contenido tienen los derechos fundamentales. Sin embargo, como se verá en este trabajo, ese marco conceptual no parece del todo estable a efectos de entender -en términos analíticos- los derechos fundamentales, ni puede dar cuenta de la práctica jurídica en los casos "iusfundamentales".

En lo que sigue realizaré una exposición acerca del contenido de estas teorías -con sus variantes en cada uno de $\operatorname{los} \operatorname{casos}^{2}-$ a la par de algunas críticas que cabe plantear a estas. La idea general es mostrar que, contrariamente a lo que podría parecer en una primera aproximación, estas teorías no brindan un terreno seguro en el que pisar. Las tesis defendidas por tales teorías pueden ser atacadas desde varios frentes. El supuesto marco conceptual estable que dicen ofrecer, puesto a prueba, a menudo resulta ilusorio; quizás incluso peligroso, en la medida en que esconde algunos problemas reales tras de otros aparentes. Hacia el final del trabajo se indicará por qué resulta preferible una alternativa realista $\left(\right.$ moderada $\left.^{3}\right)$ a estas teorías: una alternativa que se puede decir "preferible" a las otras por ser capaz de brindar, libre de algunas asunciones dudosas, una posible reconstrucción de la práctica jurídica efectiva en los casos "iusfundamentales".

2 He realizado una primera aproximación parcial a estas teorías en MALDONAdo MuÑoz, M. Conflictivismo y anti-conflictivismo en los derechos fundamentales. En Diritto \& questioni pubbliche. 16, 2, 2016, 105-131.

3 Como yo lo veo, hay dos formas en que una teoría realista moderada se distingue de una teoría realista radical. En el primer caso, à la Guastini, el realismo se dice moderado en el sentido de que se distingue -en términos descriptivos- la "interpretación" de la "construcción jurídica" (la "interpretación" stricto sensu es aquella en donde el significado atribuido a una cierta disposición se puede reconducir al discurso del legislador dentro de un marco de interpretaciones plausibles; la "construcción", por su parte, se aleja de este marco de interpretaciones plausibles, constituyéndose, así, en una genuina "creación" de derecho). Para el realismo radical, por su parte, todo ejercicio interpretativo es, en cambio, "creativo" de significado. Véanse, en general, GUASTINI, R. Interpretare e argomentare. Milano: Giuffrè, 2011, 424 ss.; GuASTINI, R. Interpretación y construcción jurídica. En Isonomía, 43, 2015, 11-48). En el segundo caso, à la Ferrer Beltrán, el realismo moderado se distingue del realismo radical en la medida en que el primero admite la posibilidad del error interpretativo en cuanto que el derecho es entendido como el producto de una especie de convención interpretativa (rectius, de un conjunto de convenciones interpretativas), en donde la tesis "el derecho es lo que dicen los jueces" es vista como radical solo en la medida en que se entienda que el derecho es lo que dice "cada uno de los jueces", y moderada en la medida en que se ate la interpretación "correcta" del derecho a la existencia de dichas convenciones (convergencias interpretativas). Véase FERRER BELTRÁN, J. El error judicial y los desacuerdos irrecusables en el derecho. En LuQue SÁnchez, P. y RAtti, G. B. (eds.), Acordes $y$ desacuerdos. Madrid: Marcial Pons, 2012. En mi opinión, es posible combinar ambas tesis moderadas, pero aquí no argumentaré al respecto. En todo caso, véase MALDONADo MuÑoz, M. El realismo jurídico (apuntes para una introducción). En Iuris Dictio. 25, 2020, 13-25. 


\section{TEORÍAS DE LOS LÍMITES DE LOS DERECHOS}

Hay dos teorías generalmente aceptadas sobre los límites de los derechos: la de los límites externos y la de los límites internos. El problema que estas teorías apuntan a resolver se circunscribe a la "naturaleza" y a la "forma" de los límites de los derechos, así como a la manera de su (de)limitación. En este modo de ver el problema, los derechos pueden ser concebidos como "derechos por limitar", por un lado, o como "derechos ya delimitados", por otro. En el primer caso, los límites no aparecen (siempre) dados; en el segundo, en cambio, forman parte del mismo contenido del derecho. Para la primera teoría, los derechos se encuentran en conflicto; para la segunda, no ${ }^{4}$.

\subsection{Teoría de los límites externos}

Se habla de la teoría de los límites externos en referencia a la visión que sostiene que los límites de los derechos son definidos "desde fuera", en dos momentos distintos, referentes a dos objetos jurídicos diversos: un primer momento en que aparecen ciertos derechos prima facie (por ende, todavía no limitados), y un segundo momento en que los derechos son ya delimitados o se encuentran definidos ${ }^{5}$. Esta es una teoría de la legitimidad de las restricciones de los derechos fundamentales. No es que en esta posición exista una relación necesaria entre el concepto de derecho y el de restricción -bien lo explica Alexy-, sino que la relación es creada ${ }^{6}$, es decir, artificial y funcional a la concepción propia de la teoría de los límites externos. Creo que este modo de afrontar el problema se puede entender de modo más o menos claro a través de las siguientes afirmaciones de Bernal Pulido (quien es, junto a Alexy, uno de los prosélitos de la teoría):

Existe una colisión entre principios, cuando en un caso concreto son relevantes dos o más disposiciones jurídicas, que fundamentan prima facie dos normas incompatibles entre sí, y que pueden ser propuestas como soluciones para el caso. Se presenta una colisión entre principios, por ejemplo, cuando los padres de una niña, que profesan el culto evangélico, y en razón del respeto a los mandamientos de esta doctrina religiosa, se niegan a llevarla al hospital, a pesar de que corre

4 Para un análisis de seis posiciones diversas acerca del "problema del conflictivismo", esto es, el debate entre conflictivistas y anticonflictivistas en el marco de los derechos fundamentales, véase MALdonado MuÑoz. Conflictivismo y anti-conflictivismo en los derechos fundamentales, cit. Para una aproximación de teoría de conjuntos, véase MALdonado MuÑoz, M. Principi, diritti fondamentali e teoria degli insiemi. En Materiali per una storia della cultura giuridica. XLIX (2), 2019, 535-556.

5 Borowski, M. La estructura de los derechos fundamentales. Bogotá: Universidad Externado de Colombia, 2003, 66-68.

6 AleXy, R. Teoría de los derechos fundamentales. Madrid: Centro de Estudios Constitucionales, 1993, 269. 
peligro de muerte. Si referimos este caso al derecho constitucional colombiano, observaremos que las disposiciones de los artículos 19 y 16 de la Constitución, que establecen, respectivamente, la libertad de cultos y el derecho al libre desarrollo de la personalidad, fundamentan un principio que en la mayor medida posible permite decidir a los padres, si de acuerdo con sus creencias deben llevar o no a sus hijos al hospital. Este principio entra en colisión con los principios del derecho a la vida y a la salud de la niña, establecidos por los artículos 11, 44 y 49 de la Constitución, que ordenan proteger la vida y la salud de los niños en la mayor medida posible. La incompatibilidad normativa se presenta en este caso, porque, de los artículos 19 y 16 se deriva que está permitido prima facie a los padres de la niña, decidir si la llevan o no al hospital, mientras que de los artículos 11, 44 y 49 se sigue que llevar a la niña al hospital, es una conducta ordenada prima facie por los derechos fundamentales ${ }^{7}$.

Pensada de ese modo, esta postura puede compararse -como algunas veces ya se ha hecho ${ }^{8}$ - con la idea de W. D. Ross sobre los "deberes prima facie". Este concepto, que pretendía retar a la concepción kantiana conforme a la cual los deberes no se presentan al mismo tiempo ${ }^{9}$ (que influyó incluso en Kelsen hasta 1960), aparece por primera vez en The Right and the Good, de 1930, como sigue:

Sugiero 'deber prima facie' o 'deber condicional' como una breve forma de referirse a la característica (muy distinta de la de ser un deber propiamente dicho) que un acto tiene en virtud de ser de un cierto tipo (por ejemplo, el mantenimiento de una promesa), de ser un acto que podría ser un deber propiamente dicho, si no fuera a la vez de otro tipo que es moralmente significativo. Si un acto es un deber propiamente dicho o un deber real depende de todos los tipos moralmente significativos de los que ese acto es una instancia ${ }^{10}$.

En el caso específico de la teoría en examen, la idea de ciertos derechos prima facie - nacidos de una primera limitación-sería una versión invertida

7 Bernal Pulido, C. Estructura y límites de la ponderación. En Doxa. 26, 2003, 226.

8 Véase, v.gr., Bongiovann, G. Principi come valori o come norme: interpretazione, bilanciamento e giurisdizione costituzionale in Alexy e Habermas. En Ars Interpretandi. 10, 2006, 177-198; GorRa, D. Crítica a la teoría de la argumentación jurídica de Robert Alexy: sistema de ponderación de principios. En Nuevas Fronteras de Filosofía Práctica. 3, 2014.

9 Dice Kant, I. The Metaphysics of Morals (1797). New York: Cambridge University Press, 1991, 50: "Un conflicto entre deberes (collision officiorum s. obligationum) sería una relación entre ellos en la que uno eliminaría al otro (en todo o en parte). Pero desde que deber y obligación son conceptos que expresan la necesidad práctica objetiva de ciertas acciones y dos reglas opuestas entre ellas no pueden ser necesarias al mismo tiempo, si hay un deber de actuar de acuerdo con una regla, actuar de acuerdo con la regla opuesta no es un deber sino incluso lo contrario al deber; de modo que una colisión de deberes es inconcebible (obligationes non colliduntur)".

10 Ross, W. D. The Right and the Good (1930). Oxford: Clarendon Press, 2002, 19-20. 
pero correspondiente a la de los deberes prima facie. La concepción de Ross ha sido acusada de inconsistente ${ }^{11}$. Pero, dejando este asunto específico a un lado, las coincidencias entre una aproximación y otra -entre la de Ross y la de los defensores de la teoría de los límites externos- no parecen ser insignificantes. Si esto es así, bien se podría decir -bajo la hipótesis de la correlatividad $^{12}$ - que a todo derecho prima facie corresponde un deber prima facie $^{13}$. Claro que estos, según los casos, podrían no revelarse al final como "verdaderos" deberes o derechos (como deberes o derechos "propiamente dichos"), según se cumplan o no las condiciones o instancias que se deben constituir para tal calificación. (“'Prima' facie -dice Ross- sugiere que se está hablando solamente de la apariencia que una situación moral presenta a primera vista, y que puede llegar a ser ilusoria; mientras que yo estoy hablando de un hecho objetivo que está involucrado en la naturaleza de la situación, o más estrictamente en un elemento de su naturaleza, aunque no surja de toda su naturaleza, como un deber hace efectivamente" ${ }^{14}$ ).

La razón para denominar a los derechos como prima facie estriba en la asunción de que estos corresponden a otras tantas "posiciones prima facie" de las personas con relación a tales derechos ${ }^{15}$. (Las "posiciones prima facie", en Alexy, son caracterizadas por oposición a las "posiciones definitivas": una posición prima facie, a diferencia de una definitiva, no expresa un estatus más o menos inmóvil del titular de un derecho, sino que lo fundamenta "en principio". Si es o no posible determinar siempre estas "posiciones" es una cuestión que no parece interesar demasiado a la teoría, que en este caso procede a tientas). Aun así, el derecho prima facie no es sino el primer momento de la teoría de los límites externos. Lo que "constituye" a un derecho propiamente dicho es la delimitación, que no es otra cosa que el momento de la restricción legítima de un derecho fundamental: el momento en que un derecho prima facie se convierte en un derecho ya delimitado (un derecho tout court). Alexy aclara, en cualquier caso, que la relación entre derechos y restricciones que defiende esta teoría, no siendo necesaria desde el punto de vista conceptual, se da por una "necesidad externa" a los derechos mismos:

11 Searle, J. Prima facie obligations. En Raz, J. (ed.), Practical Reasoning. Oxford: Oxford University Press, 1978.

12 Maldonado Muñoz, Mauricio. Los derechos fundamentales. Un estudio conceptual. Santiago de Chile: Olejnik, 2018, 91 ss.

13 Que conformarían, así, un ius perfectum prima facie. Vale la pena, en cualquier caso, echar un vistazo también a la noción de "derechos" y al tratamiento que sobre su correspondencia con los deberes realiza el mismo Ross en el Apéndice I de su libro: llamado, justamente, "Rights". Ross. The Right and the Good, cit., 48-56.

14 Ibid., 20.

15 AlEXY, R. Teoría de los derechos fundamentales. Madrid: Centro de Estudios Constitucionales, 1993, 268-269. 
“compatibilizar los derechos de los diferentes individuos como así también los derechos individuales y los bienes colectivos" $"$.

\subsection{Teoría de los límites internos}

La teoría de los límites internos sostiene que, por su misma función, fines y naturaleza, los derechos tienen fronteras inmanentes ${ }^{17}$, de modo que lo que queda fuera de estas está también fuera del derecho "correctamente" concebido. En ese sentido, los límites se delinean internamente y se entiende que son previos, inherentes y consustanciales a los derechos. Así, resulta que hablar de restricciones es, sin más, incorrecto. Si los derechos son vistos desde la teoría de los límites externos hay "restricciones legítimas"; si son vistos desde la teoría de los límites internos hay (a priori) "delimitaciones internas" ${ }^{18}$. Dice Orrego Sánchez:

[Una de las fórmulas propuestas] en el marco de la argumentación iusfundamentalista consiste en establecer límites externos a los derechos. Los derechos se formulan, entonces, siempre como limitados por algún límite configurado de manera abierta: los derechos de los demás, el bienestar general, el orden público... No hay nada que objetar a la formulación general, que refleja el carácter limitado de los derechos humanos; pero estas fórmulas no solucionan el problema hermenéutico, que se traslada a la fijación de esos límites ya sea en general, ya sea en concreto ${ }^{19}$.

De la "fijación de estos límites", la teoría de los límites internos se ocupa respondiendo que los derechos, en realidad, no se limitan: no hay nada que limitar pues ellos están ya desde el inicio delimitados. (Corresponden -diría Alexy- a "posiciones definitivas" ${ }^{20}$ ). Aun así, los defensores de esta visión sostienen que los derechos no son ilimitados, puesto que deben concebirse "en su coexistencia" 21 , de modo que las fronteras de los unos se establecen necesariamente de conformidad (en armonía) con las de los demás. Aunque

$16 \quad$ Ibid., 268.

17 Borowski, M. La estructura de los derechos fundamentales. Bogotá: Universidad Externado de Colombia, 2003, 68.

18 SERna, P. y TOLLer, F. La interpretación constitucional de los derechos fundamentales. Una alternativa a los conflictos de derechos. Buenos Aires: La Ley, 2000, 70-71.

19 ORREgo SÁnchez, C. Supuestos conflictos entre derechos humanos y la especificación de la acción moral. En Revista Chilena de Derecho. 37 (2), 2010, 331.

20 AleXy. Teoría de los derechos fundamentales, cit., 269.

21 Por ejemplo, dice CоттA, S. La coexistencialidad ontológica como fundamento del derecho. En Persona y Derecho. 9, 1982, 18: "El Derecho está en condición de configurar la coexistencia (y corresponder por tanto a su fundamento) cuando mantiene su fidelidad a la justicia, que es la condición trascendental para que la norma sea universal y universalmente respetada, ya que la justicia implica la igualdad ontológica entre los individuos, la simetría entre sus derechos y deberes, la correlación entre derechos y deberes, la proporcionalidad de los méritos y deméritos 
parecería un juego de palabras, la teoría defiende justamente esto: no es que los derechos sean ilimitados, pero tampoco son stricto sensu limitados, en tanto corresponden a cierto ámbito ya dado, establecido por sus condiciones de justicia ${ }^{22}$. Un ámbito relacionado con un modo de ser derivado del "modo de ser del ser humano" "23. (Así expresada, esta es, obviamente, una posición iusnaturalista). De allí que el trabajo de los operadores jurídicos, desde este punto de vista, se reduzca prácticamente a acertar a los "linderos" (inmanentes) de los derechos.

Sobre esta teoría cabe hacer una salvedad: no es necesario que una teoría de los límites internos abrace el ideal iusnaturalista. Bastaría con abrazar, por ejemplo, un ideal garantista à la Ferrajoli, o asumir una posición exegética del ideal constitucionalista o del ideal democrático. (En algunos de estos casos la teoría de los límites internos se vería, sin embargo, atenuada $\left.{ }^{24}\right)$. Esta versión se puede ilustrar, en general, así:

Según la teoría interna $[\ldots]$ los derechos fundamentales tienen solamente un contenido definitivo fijado con anterioridad, o preformado [...] El contenido del derecho es de un tipo relativamente reducido, que está garantizado desde el inicio por las disposiciones constitucionales, y que ya ha tenido en cuenta sus límites externos. Desde este punto de vista, las restricciones a los derechos fundamentales no son necesarias; éstas ni siquiera son posibles, en la medida en que el derecho aparece como restringido desde el inicio. La expresión "derecho fundamental restringido" se vuelve, entonces, una simple redundancia o una alusión a una simple imposibilidad jurídica: una redundancia porque todo derecho fundamental presupone ya sus restricciones; o una alusión a una imposibilidad jurídica, porque si es así ningún derecho fundamental podría ser restringido, pues es imposible vaciar un derecho fundamental de una parte de contenido que no le pertenece ${ }^{25}$.

de las acciones, la imparcialidad en el juicio. En pocas palabras, la justicia da a cada uno lo suyo y no hace daño a nadie según la medida de la coexistencia".

22 Según los defensores de esta versión de la teoría de los límites internos, las fronteras de los derechos coinciden necesariamente con un ámbito en el que "es justo ejercerlos". Véase TOLLER, F. La resolución de los conflictos entre derechos fundamentales. Una metodología de interpretación constitucional alternativa a la jerarquización y al balancing test. En FERRER MACGrEGOR, E. (ed.), Interpretación constitucional. T. II. México, D.F., Porrúa, 2005, 1258-1259.

23 SERNA Y TOLLER. La interpretación constitucional de los derechos fundamentales, cit., 67. También dice Serna en otra publicación: "Si los derechos humanos son el modo histórico de concretar ciertas exigencias que garanticen al hombre una vida digna, parece que su determinación guarda relación con el modo de ser propio del hombre". SERNA, P. Derechos fundamentales: el mito de los conflictos. Reflexiones teóricas a partir de un supuesto jurisprudencial sobre intimidad e información. En Humana Iura. 4, 1994, 230.

24 Sobre el irenismo de Ferrajoli, véase Luque SÁnchez, P. La concepción irenista de la constitución. Sobre la posibilidad de una reconstrucción armónica del contenido ético-sustantivo del Estado constitucional. En Isonomía. 38, 2013, 35-65.

25 Bernal Pulddo, Carlos. Une défense de la de la forme de raisonnement juridique du néoconstitutionalisme. Pro manuscripto, 2015, 9. 
Efectivamente, como discurso ideal asumido por las democracias constitucionales contemporáneas, el discurso sobre los derechos fundamentales se presenta como si correspondiese a un estado de cosas del todo armonioso. De allí que las constituciones contemporáneas hablen -así como ya lo hicieran las antiguas declaraciones de derechos- en términos de derechos "inalienables", "inviolables", "irreductibles", y así por el estilo. Esta serie de presupuestos puede conducir, con argumentos más refinados -como los de Ferrajoli ${ }^{26}$-, o incluso más ingenuos -como los de los "repetidores" de los textos constitucionales-, a la defensa de la posición anti-conflictivista en materia de derechos ${ }^{27}$. La idea base es que los límites de los derechos, en la estructura de los modernos sistemas jurídicos, obedecen a ciertos condicionamientos que evitan que estos colisionen entre sí. Tal cosa se daría por la coincidencia de dos fenómenos: la forma de gobierno democrática y el diseño institucional propio del constitucionalismo ${ }^{28}$.

\section{TEORÍAS DEL CONTENIDO ESENCIAL}

La idea básica de las teorías sobre el contenido esencial de los derechos es dividir lo "disponible" de lo "indisponible". Lo indisponible, que coincide

26 Para un sumario de los argumentos ferrajolianos al respecto, véase Pino, G. Conflictos entre derechos fundamentales. Una crítica a Luigi Ferrajoli. En Doxa. 32, 2009, 653-656.

27 Véase Maldonado MuÑoz. Conflictivismo y anti-conflictivismo en los derechos fundamentales, cit.

28 Si bien no se puede decir que en todos los casos en donde no se abraza la teoría de los límites externos se deba seguir obligatoriamente aquella de los límites internos (por la banal razón de que muchos teóricos tratan el problema en otros términos), se puede decir que hay un "parecido de familia" entre todas las teorías que aspiran, de uno u otro modo, a encontrar una especie de concordancia entre los derechos mirando dentro de su "estructura misma", sea esta producto solo de sus aspiraciones o de un diseño institucional y conceptual más complejo. No es necesario llegar a defender una posición iusnaturalista, como ya se dijo, pero la idea más genérica según la cual los límites externos provocan malentendidos en relación con la "naturaleza" de los derechos está siempre presente. En esta segunda variante de la teoría de los límites internos, uno de los blancos más importantes de la polémica ha sido -justamente por su amplia notoriedad- Ferrajoli: Comanducci, Pino, Barberis, Orunesu, Ruiz Manero, entre otros, han criticado la forma en que Ferrajoli ha tratado el problema de los conflictos; véanse CoMANDUCCI, P. Problemi di compatibilità tra diritti fondamentali. En Analisi e diritto. 2002-2003, 317-329; Pino, G. Conflictos entre derechos fundamentales. Una crítica a Luigi Ferrajoli. En Doxa. 32, 2009, 649-650; BARBERIS, M. Ferrajoli, o el neoconstitucionalismo no tomado en serio. En Doxa. 34, 2011, 89-93; ORunesu, C. Los conflictos entre derechos y el derecho internacional en la jurisprudencia de la CSJN. Pro manuscripto, 2014; Ruz MANero, J. Due problemi per la ponderazione: tensioni irrisolvibili e principi imponderabili. En LuQue SÁNCHEZ, P. y SCAMARDELla, F. (eds.), Gli argomenti del costituzionalismo: la tensione tra etica e diritto. Napoli: Editoriale Scientifica, 2014. La discusión se puede advertir incluso en un más o menos reciente libro publicado por Il Mulino en donde -en una conversación con Barberis- Ferrajoli se reafirma en su visión sobre el problema, diciendo precisamente lo siguiente: "los conflictos existen. Pero en una medida incomparablemente inferior a cuanto se complacen en dramatizar neoconstitucionalistas y iusrealistas". Ferrajoli, L. Dei diritti e delle garanzie. Conversazione con Mauro Barberis. Bologna: Il Mulino, 2013, 87. 
con el contenido esencial de los derechos; y lo disponible, que es lo que queda fuera de tal contenido. Tres teorías se refieren al (así llamado) contenido esencial de los derechos fundamentales: una sostiene que el contenido esencial es "inmóvil" y "absoluto", otra dice que es "móvil" y "relativo", y una tercera defiende que tal contenido esencial coincide con el "contenido mismo" de los derechos ${ }^{29}$.

Antes que nada, cabe decir que si se asume que hay un contenido esencial, se entiende que existe otra parte no esencial: así, el derecho se movería entre lo esencial y lo no esencial, lo nuclear y lo accesorio, lo necesario y lo contingente. Según algunos ${ }^{30}$, esta garantía -así también suele ser considerada- habría sido anticipada ya por la Constitución argentina $(1853)^{31}$, que en su artículo 28 reza: "Los principios, garantías y derechos reconocidos en los anteriores artículos, no podrán ser alterados por las leyes que reglamenten

29 Se habla de contenido esencial de los derechos haciendo alusión al texto del artículo 19, segundo inciso, de la Ley Fundamental alemana (1949), que dice: "En ningún caso un derecho fundamental podrá ser afectado en su contenido esencial". La expresión aparece también en la Constitución portuguesa (1976), específicamente en el artículo 18, inciso tercero, así: "Las leyes restrictivas de los derechos, libertades y garantías habrán de revestir carácter general y abstracto y no podrán reducir la extensión y el alcance del contenido esencial de los preceptos constitucionales". Asimismo, en la Constitución española (1978), en su artículo 53, primer inciso, que señala: "Sólo por ley, que en todo caso deberá respetar su contenido esencial, podrá regularse el ejercicio de tales derechos y libertades". Y también en la Carta Europea de Derechos Humanos (2000), que en su artículo 52, inciso primero, dice: "Cualquier limitación del ejercicio de los derechos y libertades reconocidos por la presente Carta deberá ser establecida por la ley y respetar el contenido esencial de dichos derechos y libertades". Hoy por hoy, además, el así llamado contenido esencial ha pasado de los textos constitucionales a las diversas decisiones jurisprudenciales adoptadas por las cortes constitucionales y supremas de varios países del mundo; en algunos casos incluso allí donde no está previsto expresamente en la normativa. Algunos ejemplos de la jurisprudencia: en el caso alemán véanse, v.gr., las sentencias del Tribunal Constitucional Federal: BVerfGE 6, 32 [Wilhelm Elfes], BVerfGE 34, 238 [Reproducción de una grabación secreta], BVerfGE 39, 1 [Interrupción del embarazo I], BVerfGE 93, 266 [Los soldados son asesinos], BVerfGE 69, 315 [Libertad de reunión - Brokdorf], BVerfGE 84, 212 [Cierre patronal - Aussperrung], BVerfGE 7, 377 [Ley sobre Farmacias], BVerfGE 109, 279 [Vigilancia acústica del domicilio particular], BVerfGE 58, 300 [Extracción de arena y grava]. En el caso italiano véanse, $v$.gr., las sentencias de la Corte Constitucional: 1146/1988 [Vilipendio della bandiera], 80/2010 [Diritto all'istruzione], 10/2010 [Assistenza a cittadini meno abbienti], 185/1998 [Diritto alla salute]. En el caso español véanse, $v . g r$., las sentencias del Tribunal Constitucional: 11/1981 [Derecho de huelga], 99/1985 [Tutela judicial efectiva], 115/1987 [Derechos y deberes de los extranjeros en España], 101/1991 [Libertad sindical]. En el ámbito de la teoría constitucional suele destacarse, ante todo, el texto de HäBerle, P. La garantía del contenido esencial de los derechos fundamentales en la Ley Fundamental de Bonn. Madrid: Dykinson, 2003.

30 Véase, inter alia, SAPAG, M. El principio de proporcionalidad y de razonabilidad como límite constitucional al poder del Estado: un estudio comparado. En Dikaion, 17, 2008, 184.

31 Esta afirmación, por otro lado, ha sido contestada. Véase MichaEL, L. ¿El contenido esencial como denominador común de los derechos fundamentales en Europa? En ReDCE. 6 (11), 2009, 166. En todo caso, téngase en cuenta que el artículo 28 de la Constitución argentina fue inspirado por el artículo 20 del proyecto alberdiano de constitución en donde sí se habla de “esencia”. Véase LinAREs, J. Razonabilidad de las leyes. Buenos Aires: Astrea, 2010, 160. En ese sentido, la objeción de Michael puede ser relativizada. 
su ejercicio". Se dice esto porque de este artículo se puede extraer un principio de inalterabilidad de los derechos constitucionales ${ }^{32}$, o bien -se estila decir- un principio de no restricción de los derechos (principio del que, por otra parte, la Corte Suprema argentina ha "derivado" también el así llamado "principio de razonabilidad" ${ }^{33}$ ). Tal equiparación entre "contenido esencial" e "inalterabilidad" es, sin embargo, imprecisa: se trata de cosas diversas. Sobre todo, nótese que, si se toma en cuenta la teoría de los límites externos antes referida, esta parece coincidir con la noción misma de contenido esencial (desde el momento en que tal teoría admite algunas restricciones legítimas), mientras que un principio de inalterabilidad o de no restricción solo puede coincidir con la segunda, o sea la teoría de los límites internos de los derechos (al menos, en sentido estricto, en una de sus versiones: la iusnaturalista). Existen, entonces, dos visiones diferentes: la teoría del contenido esencial y la teoría de la inalterabilidad de los derechos ${ }^{34}$. Mientras en la segunda postura no se advierten posiciones divididas dentro de la misma, existen dos versiones diferentes de la teoría del contenido esencial en sentido estricto: una que defiende un contenido esencial "absoluto" y otra que defiende un contenido esencial "relativo".

\subsection{Teoría absoluta del contenido esencial}

La teoría absoluta del contenido esencial sostiene, sustancialmente, que en cada derecho se presenta un núcleo duro ("contenido nuclear") en el cual se pueden verificar las "notas esenciales" de ese derecho: aquello que lo distingue de modo particular respecto de otros derechos, sus rasgos y contenido "necesarios". Este núcleo duro sería indisponible, mientras que lo que queda fuera de este podría ser parte (legítimamente) de las regulaciones del legislador y de las decisiones de los jueces. En esta teoría, el contenido esencial es inmóvil y permanente, por lo que "se excluye de la ponderación un núcleo imponderable de los derechos fundamentales"35. Según este modo de ver el problema, si es dable ponderar, esto solo puede ocurrir (legítimamente) fuera del "núcleo" del derecho.

32 Toller, F. Los derechos in concert: 'metodologías para tomar decisiones armonizadoras en casos entre derechos y bienes constitucionales'. En CiancIardo, J. (ed.), Constitución, neoconstitucionalismo y derechos: teoría y aplicaciones en la interpretación de los derechos constitucionales. México, D.F.: Porrúa, 2012, 122.

33 Véase SAPAG, M. El principio de proporcionalidad y de razonabilidad como límite constitucional al poder del Estado: un estudio comparado. En Dikaion, 17, 2008, 157-198.

34 Y entonces -en esta segunda variante- del "contenido" y basta, o al menos así lo expresan sus defensores. Dicen SERNA y TOLLER. La interpretación constitucional de los derechos fundamentales, cit., 47: "Identificamos, pues, contenido esencial con el contenido del derecho, prescindiendo de núcleos duros y periferias disponibles".

35 Michael, L. ¿El contenido esencial como denominador común de los derechos fundamentales en Europa? En ReDCE. 6 (11), 2009, 180. 
En líneas generales, esta teoría puede ser sintetizada del modo siguiente:

a) El contenido esencial brinda una protección en sentido fuerte. Como el nombre de la teoría lo indica, es una protección absoluta, que no cede ante nada [...]

b) El contenido esencial es una parte o núcleo duro del derecho fundamental. Cada derecho fundamental tiene un sector afectable por el legislador y otro inmune a su actuación $[\ldots]$

c) El contenido no esencial no queda absolutamente disponible para el legislador: cualquier intervención legislativa en este ámbito debe superar el test de proporcionalidad. La diferencia estriba en que la intervención en la parte esencial del derecho fundamental queda vedada por la garantía de dicho contenido, y no puede justificarse por la razonabilidad ${ }^{36}$.

En esta teoría, el "núcleo duro" suele representarse con un dibujo en que aparece un círculo más pequeño dentro otro más grande que lo contiene, ambos concéntricos. El más pequeño representa el "contenido esencial absoluto del derecho": la parte externa a este, pero interna al más grande, no pertenece al espacio reservado a dicho "núcleo duro", pero se entiende que hace parte del derecho ampliamente considerado. Es en esta última parte, y solamente en esta, donde las restricciones pueden darse: así, el contenido del derecho podría variar según las diferentes regulaciones; salvo, por supuesto, en su ámbito nuclear. Toda interferencia (i.e., toda violación a dicho contenido esencial y absoluto) es, según esta teoría, ilegítima.

\subsection{Teoría relativa del contenido esencial}

En la teoría relativa del contenido esencial dicho contenido no es inmóvil, sino móvil. Por contenido esencial, en esta visión, se quiere decir "contenido pasado por el examen de proporcionalidad". Y entonces, en ese sentido, ponderado en relación con otros derechos y bienes públicos. En otras palabras, mientras una injerencia es proporcionada (ponderada) no hay afectación al contenido esencial. Se puede decir, así, que esta es una posición caracterizada por la tesis siguiente: "la esencia de los derechos fundamentales es su relatividad. Los derechos son ponderables y deben ser ponderados" ${ }^{37}$. Se advierte rápidamente la diferencia entre la teoría absoluta del contenido esencial y aquella relativa: en este último caso, la ponderación bien puede aplicarse a un hipotético "núcleo duro".

36 CiAnCIARDo, J. El ejercicio regular de los derechos: análisis y crítica del conflictivismo. Buenos Aires: Ad-Hoc, 2007, 261-263.

37 Michael, L. ¿El contenido esencial como denominador común de los derechos fundamentales en Europa? En ReDCE. 6 (11), 2009, 177. 
La teoría relativa del contenido esencial se suele representar con un círculo más grande y diversos círculos más pequeños que oscilan en su interior y que pueden abarcar, sea un espacio, sea otro, según el contenido resultante de las ponderaciones aplicadas a ellos. Así, en unos casos, un círculo representará un contenido esencial relativo (móvil), mientras que en otros podrá servir de representación otro círculo ubicado en una parte diversa. En cada caso, el contenido esencial relativo es indisponible: lo que le es externo -siendo, en todo caso, interno al círculo más grande- puede ser restringido (i.e., puede hacer parte de las regulaciones del legislador o de las decisiones de los jueces). La condición es, nada más, que sea legítimamente ponderado con otros derechos o bienes públicos. Sobre todo, en esta segunda versión -aunque no se excluye en la primera- la idea del contenido esencial se ha vinculado con el así llamado principio de proporcionalidad (a veces asimilado al principio de razonabilidad $)^{38}$.

Vale la pena anotar lo siguiente: el principio de proporcionalidad, desde sus albores en Europa continental, hacía referencia a la aplicación de (al menos) tres subprincipios: el de idoneidad, el de necesidad y de proporcionalidad en sentido estricto ${ }^{39}$. En general, a este suele estar atado el método de la ponderación ${ }^{40}$. En el caso del principio de razonabilidad, en cambio, la cuestión ha oscilado: del principio de razonabilidad entendido como substantive due process of law (propio del derecho estadounidense) ${ }^{41}$ al principio de razonabilidad entendido como equivalente al principio de proporcionalidad de los europeos ${ }^{42}$. Además, dado que la Corte Suprema de Justicia de la Nación

38 Véase, en general, Cianciardo, J. El principio de razonabilidad. Del debido proceso sustantivo al moderno juicio de proporcionalidad. Buenos Aires: Ábaco, 2009.

39 Véase Clérico, L. El examen de proporcionalidad: entre el exceso por acción y la insuficiencia por omisión o defecto. En CARBONELL, M. (ed.), El principio de proporcionalidad y la interpretación constitucional. Quito: Ministerio de Justicia y Derechos Humanos, 2008.

40 Véanse Alexy, R. La fórmula del peso. En Carbonell, M. (ed.), El principio de proporcionalidad y la interpretación constitucional. Quito: Ministerio de Justicia y Derechos Humanos, 2008; Bernal Pulido, C. Estructura y límites de la ponderación. En Doxa. 26, 2003, 225-238; Bernal Pulido, C. La racionalidad de la ponderación. En Carbonell, M. (ed.), El principio de proporcionalidad y la interpretación constitucional. Quito: Ministerio de Justicia y Derechos Humanos, 2008; Moreso, J. J. Alexy y la aritmética de la ponderación. En CARBonell, M. (ed.), El principio de proporcionalidad y la interpretación constitucional. Quito: Ministerio de Justicia y Derechos Humanos, 2008; PRIETO SANCHÍs, L. El juicio de ponderación constitucional. En CARbonell, M. (ed.), El principio de proporcionalidad y la interpretación constitucional. Quito: Ministerio de Justicia y Derechos Humanos, 2009.

41 Véase Linares, J. Razonabilidad de las leyes. Buenos Aires: Astrea, 2010.

42 Véase Cianciardo. El principio de razonabilidad, cit., 27. Por otro lado, se habla de tres subprincipios del principio de proporcionalidad (o de "razonabilidad", en el caso en que coinciden). Estos tratan de atar, en toda regulación, los medios a los fines. Los explicaré brevemente: (1) Idoneidad o adecuación. Conforme a este subprincipio, una determinada regulación debe poder lograr el fin (constitucionalmente legítimo) que se supone que persigue. Este es, en general, un análisis de la eficacia del medio: aquí importa la existencia de una relación clara de medio a fin, en cuanto dicho medio debe poder alcanzar el cometido (supuestamente) pre- 
argentina ha "derivado" el principio de razonabilidad del artículo 28 de la Constitución de ese país, también se ha entendido al principio de conformidad con la teoría de la "no restricción" o de la "inalterabilidad de los derechos" En otros casos, el principio de razonabilidad ha sido tratado en términos de otros juicios, como el de igualdad ${ }^{44}$, incluso en los términos del así llamado "sistema de escrutinios" 45 (i.e. - -se puede decir banalmente-, el substantive due process of law del principio de igualdad según la jurisprudencia de la Corte Suprema de los Estados Unidos de América).

\subsection{Teoría de la inalterabilidad del contenido de los derechos}

Para la teoría de no restricción o de inalterabilidad del contenido de los derechos solo se puede hablar de "contenido del derecho", con prescinden-

visto por la norma o la regulación que sea. En este terreno todavía no se analizan los aspectos relativos a la "justicia" del medio, sino solo los atinentes a la posibilidad (fáctica) de que dicho medio pueda realizar un determinado fin establecido por la constitución (o por los intérpretes, en conformidad con la constitución). (2) Necesidad. El análisis de necesidad supone verificar si el medio escogido para lograr el fin establecido (además de ser idóneo y eficaz) es eficiente. Se busca que el medio no sea, en lo posible, restrictivo; o que sea el menos restrictivo de entre todos los mecanismos igualmente eficaces, idóneos o adecuados. Se busca, entonces, que una regulación (sea esta legislativa o judicial) optimice los medios: que los legisladores y los jueces, en su caso, no se limiten a comprobar que el medio elegido pueda lograr el fin previsto -que no escojan cualquier medio- sino que elijan uno que represente, en la medida de las posibilidades, el mejor de los medios igualmente eficaces (el que menos sacrificios suponga dentro de las circunstancias determinadas). (3) Proporcionalidad stricto sensu. Con este juicio se busca realizar un examen de los costes respecto de los beneficios de la aplicación de una cierta medida. La cuestión primordial es verificar que entre unos y otros (costes y beneficios) se produzca cierta relación de equilibrio. Se trata, en fin, del cálculo y la comparación entre "dos intensidades o grados, el de realización del fin de la medida examinada y el de la afectación del derecho fundamental". Bernal Pulido, C. El derecho de los derechos. Bogotá: Universidad Externado de Colombia, 2008, 136. En este juicio importa, sobre todo, el aspecto relativo a la justicia del medio usado en relación con la afectación que produce. De allí que se sostenga que, conforme al subprincipio de proporcionalidad, "se prohíbe que una afectación intensa de la libertad o de otro derecho fundamental sea correlativa tan sólo a una protección mínima o leve de otro derecho o bien jurídico" (ibid.).

43 Véase SAPAG, M. El principio de proporcionalidad y de razonabilidad como límite constitucional al poder del Estado: un estudio comparado. En Dikaion, 17, 2008, 157-198.

44 Véase, v.gr., Nino, C. S. Fundamentos de derecho constitucional. Buenos Aires: Astrea, 2005, 419. También en el caso de la Corte Constitucional italiana el principio de razonabilidad suele ser entendido en los términos del principio de igualdad. Véanse GuAstinI, R. Distinguendo ancora. Madrid: Marcial Pons, 2013, 258-260; CARTABIA, M. I principi di ragionevolezza e proporzionalità nella giurisprudenza costituzionale italiana. En Conferenza trilaterale delle Corti costituzionali italiana, portoghese e spagnola. Roma: Palazzo della Consulta, 2013. En otros casos, como el alemán, el principio remite a otros principios, como el de libertad. Véase LuTHER, J. Ragionevolezza e dignità umana. En Polis Working Papers, 591. Tribunale di Alessandria, Università del Piemonte Orientale, Working Paper n. 79, 2006.

45 Véase Giardelli, L. El derecho a la igualdad y el sistema de escrutinios. Pro manuscripto, 2006. 
cia de supuestos núcleos duros o periferias disponibles ${ }^{46}$. Tal "contenido" estaría fijado por criterios de justicia que se corresponderían con el "ámbito de ejercicio razonable" de cada uno de los derechos fundamentales: una vez que tal contenido es hallado (comprendido, descubierto), el derecho ha de ser considerado "inexcepcionable" ${ }^{47}$. Esta teoría pretende equiparar "razonabilidad" a "contenido del derecho"; y estipular, por ello, una especie de "principio de razonabilidad del contenido de los derechos". La razonabilidad sería -conforme a esta visión- el criterio máximo e infranqueable de validez de las normas sobre derechos. Según esta visión, o bien los derechos corresponden a algunos principios suprapositivos (vida, libertad, dignidad, etc.), cuya razonabilidad es supuestamente intrínseca, o bien corresponden a normas positivas cuya razonabilidad (extrínseca) está sujeta al examen de concordancia con los "principios suprapositivos". Esta posición se confunde con aquella de los límites internos en cuanto parte de la existencia de fronteras, de uno u otro modo, "inmanentes" (o "inalterables"); es decir, de la idea según la cual fuera de aquellas "ni hay ni nunca hubo derecho" ${ }^{48}$. Así pues, se entendería que todo menoscabo del derecho (o sea, de su contenido mismo) sería ilegítimo. Según esta aproximación, dado que la constitución dice que los derechos son inalienables (y puesto que lo son "por su naturaleza") hay que pensar en un sistema en donde el contenido de cada derecho se corresponda con los otros, haciendo del espacio ocupado por cada uno un ámbito irreductible: libre, en fin, de intromisiones por parte de otros derechos. Lo único que el legislador está autorizado a hacer es "reglamentar" los derechos, y lo único que el juez está autorizado a hacer es "armonizarlos".

46 SERNA y TOLLER. La interpretación constitucional de los derechos fundamentales, cit., 47. En similar sentido parece expresarse Martínez-Pujalte, quien dice: "El problema central vuelve a ser, por tanto, la precisa delimitación del contenido de los derechos fundamentales, la cual puede obtenerse a través de dos vías complementarias que indicara el Tribunal Constitucional [español] en la sentencia 11/1981, que continúan siendo válidas, siempre y cuando se prescinda de la distinción entre contenido esencial y no esencial de los derechos que parecen sugerir, y se abandone por lo tanto la tesis de que el contenido esencial es 'una parte' del contenido total de los derechos". Martínez-Pujalte, A. L. La garantía del contenido esencial de los derechos fundamentales. Madrid: Centro de Estudios Constitucionales, 1997, 63. Por otro lado, dice Castillo Córdova: "ningún derecho fundamental puede significar exigir que se legitimen intromisiones o sacrificios del contenido de otro derecho fundamental. De esta manera y por principio, ningún derecho fundamental (mejor todavía, su contenido jurídico) se sobrepone para desplazar el contenido de otro derecho humano en un litigio concreto, sino que, por el contrario, en cada caso, cada derecho y todo derecho tiene un contenido que se ajusta y es compatible con el contenido de los demás derechos". CASTILlo CóRdova, L. F. ¿Existen los llamados conflictos entre derechos fundamentales? En Cuestiones Constitucionales. 12, 2005, 111. Ambas posiciones son, me parece, expresión de la misma concepción de dogmática jurídica compartida por Serna y Toller.

47 SERna y Toller. La interpretación constitucional de los derechos fundamentales, cit., 47.

48 Véase Cianciardo, J. El ejercicio regular de los derechos: análisis y crítica del conflictivismo. Buenos Aires: Ad-Hoc, 2007, 235. 
No puede, en caso alguno, restringirlos (no importa con qué argumentos o con qué métodos).

Piénsese en Orrego Sánchez cuando dice:

La misma idea de los derechos naturales implica su inalienabilidad, su inmunidad respecto de cualquier conculcación. Afirmar que las violaciones de los derechos humanos desaparecen por arte de definición, cuando los actos que los sacrifican están justificados... eso equivale a enterrar la idea racional de los derechos indisponibles ${ }^{49}$.

En este sentido, se suele decir que hay regulaciones legítimas e ilegítimas: reglamentaciones y restricciones. Reglamentar es diferente de restringir -se dice-; y mientras toda reglamentación está permitida, toda restricción está, en cambio, proscrita. Así expuesta, la teoría parece concordar con el ideal de los derechos fundamentales como son presentados -con objetivos loables, pero también retóricos- en las diferentes declaraciones de derechos y en las constituciones de los Estados contemporáneos. Aun así, la oposición entre reglamentaciones y restricciones no parece ser demasiado diferente de otras presentes en el debate; por ejemplo, entre infracciones y violaciones ${ }^{50}$, entre violaciones y restricciones ${ }^{51}$, etc. Cabe preguntarse, entonces, si no se trata solamente de un problema verbal.

La teoría de la inalterabilidad de los derechos abraza el principio de razonabilidad en uno de los sentidos antes referidos, según una fórmula en donde solo es "derecho" aquello que puede justificarse desde "la razonabilidad de su contenido". Esta doctrina parece haber sido acogida por la jurisprudencia de varias $\operatorname{cortes}^{52}$. Según esta visión, y conforme a una propuesta de Sapag, a los juicios originales del principio de proporcionalidad ${ }^{53}$ se deberían sumar otros dos: el de "finalidad" y el del "contenido esencial", entendiendo por contenido esencial el (supuesto) ámbito de ejercicio razonable del derecho.

49 ORREgo SÁNCHEZ, C. Supuestos conflictos entre derechos humanos y la especificación de la acción moral. En Revista Chilena de Derecho. 37 (2), 2010, 328.

50 Thomson, J. J. Self-defense and rights. En The Lindley Lecture. The University of Kansas, 1976; Thomson, J. J. Some ruminations on rights. En Ariz. L. Rev. 19 (45), 1977, 46-60.

51 AleXy. Teoría de los derechos fundamentales, cit., 270.

52 Desde este punto de vista, el control de razonabilidad se incluye dentro del control de constitucionalidad en cuanto las normas irrazonables resultarían per se inconstitucionales. Piénsese, por ejemplo, en Mercader Uguina cuando dice: "El factor razonabilidad es un formidable instrumento discursivo de la justicia constitucional, hasta el punto de que se ha hecho coincidir juicio de razonabilidad con juicio de constitucionalidad, tanto en su contenido como en su límite". Mercader Uguina, J. Tutela judicial efectiva, control de razonabilidad de las decisiones judiciales y "canon reforzado" de motivación en la doctrina del Tribunal Constitucional. En Revista del Ministerio de Trabajo y Asuntos Sociales. 73, 2008, 132. El principio de razonabilidad, a estos efectos, se constituye -por asunción- como el aspecto sustantivo del control de constitucionalidad.

53 Véase nota 43. 
Allí donde, de modo general, el principio de proporcionalidad en sentido estricto se relaciona con la ponderación, en este caso se relaciona con la así llamada armonización. Para esta visión, "armonizar derechos" quiere decir compaginarlos, pero sin que ello signifique postergar jamás unos por otros. Sapag sostiene: "Este examen requiere que se realice una interpretación teleológica del derecho fundamental a partir del bien jurídico protegido y su función en el sistema de los derechos, a modo de encontrar la armonización con los demás derechos y no de hacerlos entrar en conflicto" ${ }^{54}$.

\section{ALGUNAS OBSERVACIONES}

Daría la impresión de que, en varias ocasiones, algunos doctrinarios caen en la tentación de acudir a categorías del todo imprecisas, con contenido retórico, algunos dirían "metafísico", a los fines de hallar algo de paz frente a la práctica efectiva en materia de adjudicación de derechos, sobre todo de derechos fundamentales. "Esencia" es, justamente, una de estas categorías. La noción misma de esencia es del todo vaga y difícil de definir, lo cual crea de entrada algunos problemas. ¿En qué sentido? Pues bien, la teoría absoluta del contenido esencial sostiene que es posible establecer $-y$ que existe- un "núcleo duro" de cada derecho fundamental. Dicho "núcleo duro" es el "contenido esencial absoluto del derecho". Pero no queda claro cuál sería la forma de identificación del contenido de dicha "esencia (absoluta)". Se impone, entonces, preguntarse si, fuera de ciertos contenidos comunes y obvios de los derechos fundamentales en los Estados constitucionales, esta posición es capaz de identificar sistemáticamente como parte del contenido esencial algunos ámbitos que resultan más difíciles de encasillar. Si no es posible determinar este "núcleo" más allá de tales contenidos comunes, esta posición sirve para bien poco: sería, entonces, trivial.

Si se piensa, en cambio, en la teoría relativa del contenido esencial, es fácil darse cuenta de que el hecho mismo de someter los posibles "contenidos esenciales" a la movilidad que resulta de las diversas ponderaciones hace que la propia noción de "esencialidad" resulte del todo superflua. Podría decirse que, dada esta posición, el "contenido esencial" está de más, y que entonces no sirve como elemento relevante para la discusión ${ }^{55}$; resultando, así, también trivial.

Por último, el principio de inalterabilidad de los derechos -atado a la teoría de los límites internos- supone, al menos en una de sus versiones, la tesis

54 SAPAG, M. El principio de proporcionalidad y de razonabilidad como límite constitucional al poder del Estado: un estudio comparado. En Dikaion, 17, 2008, 193-194.

55 Dice Pintore, A. Democrazia e diritti. Sette studi analitici. Pisa: ETs, 2010, 148: "aquello que las cortes constitucionales llaman temerariamente 'contenido esencial' de los derechos es, justamente, una entidad controvertida, siendo precisamente el lugar en el que convergen los desacuerdos acerca de los derechos". 
de la corrección en sentido fuerte (i.e., la tesis que asume que para todos los casos hay una única respuesta correcta). Dado esto, se impone cuestionarse si tal cosa es posible; pero no solo eso, porque, incluso asumiendo que sea posible, aún cabe preguntarse: ¿cómo podremos saber que en efecto hemos atinado a esa respuesta correcta, justa y del todo razonable (al contenido objetivo del derecho)? ¿Quién podría dar fe última de que en efecto esto ha resultado así? Inclusive si se admitiera esta posibilidad, tal asunción produciría un problema ulterior: los jueces jugarían el papel de la "boca de la ley", no importa si natural o simplemente fundamental en un Estado constitucional. La cuestión relevante es que, si a los jueces se les pide "acertar" siempre en el contenido "verdadero" de los derechos, se les pide lo mismo que la mayoría de estos autores critican de una versión por lo demás arcaica del formalismo.

Y, sin embargo, tampoco la teoría de los límites externos parecería ofrecer, a ojos de un teórico del contenido esencial o de la inalterabilidad, un terreno seguro. Ello, en el sentido de que el ejercicio de delimitación externa y autoritativa parecería crear una supuesta "paradoja" ${ }^{56}$ con relación a una de las funciones que se les suele atribuir a los derechos fundamentales: la de constituirse en límites al ejercicio del poder. Se crearía, pues, una paradoja en la medida en que -asumida la delimitación autoritativa- los derechos se convertirían en "límites limitados por el limitado" ${ }^{57}$. En suma, los derechos serían límites al poder, pero limitados por el mismo poder ${ }^{58}$. Esta última parece ser una fuerte objeción a la teoría de los límites externos: habría, de hecho, una incompatibilidad entre los derechos pensados en relación con uno de sus fines generalmente atribuidos y la limitación externa y autoritativa de los mismos.

56 Naturalmente, no uso el término en "sentido técnico".

57 Cianciardo. El principio de razonabilidad, cit., 23.

58 Quizá aquí también sea del caso recordar a Marx cuando dice: "El inevitable Estado Mayor de las libertades de 1848, la libertad personal, de prensa, de palabra, de asociación, de reunión, de enseñanza, de culto, etc., recibió un uniforme constitucional, que hacía a éstas invulnerables. En efecto, cada una de estas libertades es proclamada como el derecho absoluto del ciudadano francés, pero con un comentario adicional de que estas libertades son ilimitadas en tanto en cuanto no son limitadas por los 'derechos iguales de otros y por la seguridad pública', o bien por 'leyes' llamadas a armonizar estas libertades individuales entre sí y con la seguridad pública [...] Cada artículo de la Constitución contiene, en efecto, su propia antítesis, su propia cámara alta y su propia cámara baja. En la frase general, la libertad; en el comentario adicional, la anulación de la libertad. Por tanto, mientras se respetase el nombre de la libertad y sólo se impidiese su aplicación real y efectiva -por la vía legal, se entiende-, la existencia constitucional de la libertad permanecía íntegra, intacta, por mucho que se asesinase su existencia común y corriente". Marx, K. El 18 Brumario de Luis Bonaparte (1851-1852). Madrid: Fundación F. Engels, 2003, 16. Por supuesto, la objeción de Marx se decanta también en una crítica según la cual la legislación que regulaba estos derechos lo hacía a la medida de los intereses burgueses. No voy a entrar a discutir esta crítica porque evidentemente rebasa los intereses de este trabajo. Dejo sentado, sin embargo, que la objeción que identifica la "paradoja" de los límites limitados por el poder no es nueva. 
Pues bien, no parece sencillo escapar de esta supuesta paradoja. Aunque la salida parecería estar dada por el planteamiento alexiano (i.e., que los límites de los derechos a los que esta teoría se refiere se presentan "en aras de garantizar otros límites", en pos de delimitar las restricciones legítimas, y solo estas), tal no constituye una vía de escape segura, pues la cuestión de los límites es, justamente, lo que está en discusión: que la autoridad deba compatibilizar los diferentes derechos no hace desaparecer la "paradoja" siempre que es esa misma autoridad la que decide, en último término, cuáles son estos límites (resultando, al final, en límites limitados por el limitado). Por otro lado, la coexistencia de los derechos no dice nada por sí misma: tanto es así que también los teóricos de los límites internos -como se verá más adelante- creen que los límites de los derechos (ya "dados" o "preconstituidos") son el producto -en sus esquemas conceptuales- de su necesaria "coexistencia". El ámbito de ejercicio de las autoridades, conforme a la idea generalizada, encuentra su tope o coto en el contenido de los derechos, pero los derechos están en manos, en último término, de las regulaciones y las decisiones de estas (¿cómo, de otro modo, se resolverían -jurídicamente- los "conflictos"?).

Así mirado el problema, la "paradoja" subsistiría. Frente a esto, parece que cabría intentar una vía de escape (parcial): considerar a los derechos como "límites a su limitación" o "límites de los límites"59; esto es, como un entramado de normas que disciplina la forma en que los derechos han de ser (de)limitados. Ello, en primer lugar, por el legislador; y, luego, por los jueces. Pero tampoco aquí hay garantía de éxito, puesto que, en general, los problemas que tienen que ver con la limitación de los derechos -o cualquier otro que se pueda llamar un "problema de justicia" ${ }^{60}$ - es afrontado por el derecho en términos procedimentales y de competencia. Al respecto, dice Celano:

[D]ado un problema de justicia, el derecho es una institución que transforma, o al menos tiende a transformar, la solución de un problema de este tipo en una cuestión de ejecución de procedimientos predeterminados por parte de individuos predeterminados. ¿Han de satisfacerse las pretensiones de Ticio o aquellas, que entran en conflicto con ellas, de Cayo? El acercamiento específicamente jurídico de un problema de este tipo exige que se pregunte quién es competente para juz-

59 Véase Clérico. El examen de proporcionalidad, cit., 126). Por otro lado, dice AgUIAR DE LuQue, L. Los límites de los derechos fundamentales. En Revista del Centro de Estudios Constitucionales. 14, 1993, 25: “Con la expresión 'límite de los límites' se conoce el conjunto de institutos que, en cuanto requisitos formales y materiales para las leyes restrictivas de los derechos y libertades, operan a modo de límites de la capacidad limitadora del legislador en dicha materia". Cfr. CIANCIARDO, J. El ejercicio regular de los derechos: análisis y crítica del conflictivismo. Buenos Aires: Ad-Hoc, 2007, 233.

60 Véase Celano, B. Derecho, justicia, razones. Ensayos 2000-2007. Madrid: Centro de Estudios Políticos y Constitucionales, 2009, 25. 
gar en una controversia surgida entre Ticio y Cayo, y según qué procedimiento debe ser rendido el juicio a fin de llegar a una solución de la controversia que tenga carácter jurídico (es decir, qué vale, desde el punto de vista jurídico, como una decisión que produce consecuencias... sobre derechos y obligaciones de las partes...) [...] En general, el derecho tiende a transformar todo problema del tipo 'qué exige la justicia en la situación S1 (en situaciones del tipo S)' en un problema del tipo 'quién es competente para decidir, y según qué procedimiento, qué le es debido a cada uno en S1 (en situaciones del tipo S) ${ }^{61}$.

El derecho, a pesar de los ideales que pueda llegar a perseguir según se plantee en cada sistema jurídico, está determinado por esta cuestión procedimental y de competencia en la que, más allá de la cuestión de la corrección, se encuentra el problema de la respuesta final: los jueces de última instancia (lato sensu), en particular, adoptan decisiones finales (últimas) que inciden directamente, y en último término, sobre los derechos y las obligaciones jurídicas de las partes en conflicto. ("Los pronunciamientos de autoridades interpretativas cuentan como derecho por lo que al juego [del derecho] respecta"62). Estos "procedimientos" y los "jueces" son categorías jurídicas, de modo que están previstas por el derecho, que es de donde los juzgadores obtienen un marco jurídico para adoptar sus decisiones; pero los jueces, sobre todo en el caso de aquellos de última instancia, frecuentemente toman decisiones fuera del sistema de las fuentes, o las interpretan en modos diversos según las diferentes circunstancias y épocas ${ }^{63}$. ¿Qué hace que los jueces no abusen de este poder potencialmente ilimitado? ¿Un sólido diseño institucional, una serie de contraintes (como creen los realistas parisinos ${ }^{64}$ ), unos jueces virtuosamente democráticos? Parece claro, en todo caso, que la "paradoja" de los límites-limitados no tiene una vía de escape segura: no se ve cómo, de manera completa y consistente, se pueda huir de esta especie de cul-de-sac en la que la teoría de los derechos fundamentales -como, por lo demás, todo el derecho- está enfrascada ${ }^{65}$.

61 Ibid.

62 Ibid., 162-163.

63 Véanse, en general, TARello, G. L'interpretazione della legge. Milano: Giuffrè, 1980; Guastini, R. Interpretare e argomentare. Milano: Giuffrè, 2011; CHIAssoni, P. Técnicas de interpretación jurídica. Breviario para juristas. Madrid: Marcial Pons, 2011.

64 Véanse TROPER, M. Una teoria realista dell'interpretazione. En Materiali per una storia della cultura giuridica. XXIX (2), 1999, 473-493; BARBERIS, MAURO. Realismo jurídico continental. En Fabra, J. y NúÑ̃z VAquero, Á. (eds.), Enciclopedia de filosofía y teoría del derecho. Vol. 1. México, D.F.: Unam, 2015. (En una traducción más o menos fiel, contraintes se podría traducir como "vínculos" o "restricciones". En este caso, los vínculos o restricciones de diverso tipo que impiden, de hecho y de derecho, que los jueces decidan con "absoluta" libertad).

65 Véase Celano, B. Derecho, justicia, razones. Ensayos 2000-2007. Madrid: Centro de Estudios Políticos y Constitucionales, 2009, 23-59, 145, 151-169, 281-299. 
Para los teóricos de los límites internos esta constatación resultaría difícil de asimilar. Para ellos, cada derecho tiene un determinado contenido, y cualquier restricción a aquel implica un desmedro de la idea misma de derecho fundamental. Esta serie de tesis implica sostener que hay un contenido "verdadero" ("correcto", "objetivo", "justo", "razonable") de cada derecho y de los derechos en general. Claro que, más allá de estos contenidos, podrían existir conductas aparentemente cubiertas por los derechos, pero, por esto mismo, no protegibles. En este sentido, valga repetirlo, ni los legisladores ni los jueces podrían, en esta visión, "limitar" los derechos, sino que deberían simplemente limitarse -ellos sí- a "explicitar" o a "descubrir" sus fronteras $^{66}$. Esta teoría no cae -si tomamos en cuenta el entramado conceptual que propone- en la (así llamada) paradoja de los "límites-limitados", aunque plantea serios problemas: ¿cómo es posible acertar al contenido "objetivo" 67 de los derechos sin caer en inevitables subjetivismos? Y, de otra parte, aun si se siguiera un procedimiento determinado y aparentemente objetivo, ¿ ¿sería posible estar seguros de que se ha llegado a ese contenido del todo "correcto" y "verdadero"? Para más abundar - pero esta es una objeción que vale para toda posición iusnaturalista- no se ve cómo de la forma de ser del ser humano (asumiendo que sus rasgos definitorios fuesen, en realidad, así de armónicos) se puedan "deducir" los límites de sus derechos. De este defecto adolece el iusnaturalismo en general; y, por supuesto, esta posición en particular ${ }^{68}$.

Las posiciones que defienden la existencia de supuestos contenidos esenciales, o bien la inalterabilidad de los derechos fundamentales (sea desde un punto de vista total, de sus límites internos, o parcial, de los límites externos), "pecan" -unas más, otras menos- de ideológicas, de modo que no pueden reconstruir la práctica efectiva de adjudicación en materia de derechos fundamentales. Se trata, contrariamente a lo que a algunos podría parecer, no de teorías descriptivas, sino prescriptivas; que no señalan a la práctica como es, sino como debería ser. Se trata de la distinción entre el

66 Véase Cianciardo, J. Los límites de los derechos. En Dikaion. 10, 2001, 66-73.

67 Sobre este tema, me permito remitir a las críticas que realiza, a la versión fuerte y a la versión débil de la tesis de la "única respuesta correcta", AARNIO, A. Sobre el contenido de la única respuesta correcta. En Hernández, C. A. y Ortega Gomero, S. (eds.), Hermenéutica y raciocinio jurídico. Bogotá: Universidad Libre, 2012, 35-39.

68 Recuerdo aquí a Bobbio cuando dice que "[e]s indudable que toda la tradición del pensamiento iusnaturalista se caracteriza por la idea de que el hombre tiene la facultad de establecer con certeza cuáles son las reglas de lo justo y de lo injusto". Boвbio, N. La razón en el derecho (observaciones preliminares). En Doxa. 2, 1985, 21. No hay duda de que esta teoría no es la excepción. No debe olvidarse que -como dice ZAGREBelsky, G. El derecho dúctil: ley, derechos, justicia. Madrid: Trotta, 2011,119-es propio de "cualquier visión iusnaturalista auténtica asumir la tríade: verdadero, justo, obligatorio". Más en general, véase Bоввіо, N. Giusnaturalismo e positivismo giuridico. Roma-Bari: Laterza, 2011. 
enfoque teórico y el enfoque de política del derecho ${ }^{69}$. Una reconstrucción en términos teóricos es del todo necesaria, y esto no implica -no haría falta siquiera decirlo si no fuese por la serie de malentendidos que se suelen dar entre los juristas- desclasar o restar importancia a los derechos fundamentales $^{70}$. Entender la forma y los límites de los sistemas jurídicos, con todo lo que implica, constituye un sano proceso de honestidad intelectual y teórica, incluso para tratar de hallar -donde sea posible-algunas soluciones, o para atenuar ciertos problemas. Como decía Bobbio, "antes de cambiar el mundo, sería necesario entenderlo" la "realidad" "72, y el derecho positivo y los procesos jurídicos -como dice Gianformaggio- son asuntos de la vida real ${ }^{73}$.

\section{DERECHOS FUNDAMENTALES, CASOS \\ IUSFUNDAMENTALES Y JERARQUÍAS}

La reconstrucción teórica de los procedimientos de adjudicación en materia de derechos fundamentales debe hacerse con prescindencia de varias asunciones dogmáticas presentes en el debate y que, como hemos visto, oscurecen el panorama. Una teoría del derecho libre de estas asunciones es, a mi modo de ver, una teoría realista (moderada) ${ }^{74}$. Se trata, in primis, de una teoría escéptica en materia interpretativa, por oposición a una teoría cognitivista y a una teoría ecléctica ${ }^{75}$. Y aunque a menudo los teóricos realistas son escépticos o relativistas también en materia moral ${ }^{76}$, no es necesario abrazar esta tesis para aceptar la otra en el marco de la interpretación jurídica. Esto, por dos razones. La primera, porque nuestra posición metaética es independiente de que abracemos o no cualquier forma de positivismo metodológico, así como de la plausibilidad o no de sus tesis ${ }^{77}$. La segunda, porque -como lo ha dejado claro varias veces Celano- incluso si se diera por hecho que el derecho está conformado, en primer lugar, por una serie de principios, valores

69 Comanducci, P. Principios jurídicos e indeterminación del derecho. En Doxa. 21 (II), $1998,89$.

70 En general, véase Maldonado Muñoz, Mauricio. Los derechos fundamentales. Un estudio conceptual. Santiago de Chile: Olejnik, 2018.

71 Bobbio, N. Critica filosofica o condanna politica? En Rivista di Filosofia. 1975, 135.

72 En todos los casos en donde se habla en términos de la "verdad" o la "realidad", hago alusión a la "verdad por correspondencia".

73 Gianformaggio, L. La noción de procedimiento en la teoría de la argumentación jurídica. En Doxa. 14, 1993, 167.

74 Véase Guastini, R. La sintaxis del derecho. Madrid: Marcial Pons, 2016, 19 ss.

75 Guastini, R. Interpretare e argomentare. Milano: Giuffrè, 2011, 407 ss.; CHIAssoni, P. Técnicas de interpretación jurídica. Breviario para juristas. Madrid: Marcial Pons, 2011.

76 Véase Guastini, R. Distinguendo ancora. Madrid: Marcial Pons, 2013, 225 ss.

77 Véase CARACCIOLO, R. Realismo moral vs. positivismo jurídico. En Comanducci, P. y Guastini, R. (eds.). Analisi e diritto 2000. Torino: Giappichelli, 2001, 37-44. Cfr. BuLYGIN, E. Sobre el status ontológico de los derechos humanos. En Doxa. 4, 1987, 79-84. 
y/o normas (supuestamente) objetivos, ello no supondría que el contenido último del derecho esté asimismo predeterminado; esto, en la medida en que tales principios, valores y normas estarían en manos, en último término, de autoridades interpretativas (todo problema de justicia es transformado por el derecho en un problema procedimental y de competencia, como ya hemos visto). Presupuesta la existencia de un "derecho natural" u "objetivo", el derecho positivo será algo muy distinto de la "representación (fiel o no) de un orden moral objetivo", en cuanto su contenido último está determinado por dichas autoridades, no habiendo garantía de que la concreción de dichos principios coincida con su supuesto contenido objetivo. “¿Por qué deberíamos -se pregunta Celano- ser no cognitivistas en ética para poder llamarnos iuspositivistas?"78. Las tesis aquí defendidas, entonces, son independientes de cualquier posición metaética.

Encuentro provechoso, a efectos de afrontar el problema de la reconstrucción de la práctica en materia de derechos fundamentales, acudir al concepto de "jerarquía axiológica". En algunos casos, de hecho, los teóricos (sobre todo los que defienden la teoría del contenido esencial absoluto y la teoría de la inalterabilidad de los derechos) se niegan a aceptar siquiera que el concepto de jerarquía pueda aplicarse a los derechos fundamentales. Estos derechos -dicen ellos- son todos de la misma jerarquía, y no puede ser de otra manera, a menos que se quiera ir en desmedro de la propia noción de "derechos fundamentales" $"$. La Constitución ecuatoriana -para poner otro ejemplo- señala que todos los derechos son de la misma jerarquía (art. 11 núm. 5). Y esto supone -piensan algunos- que existiría una imposibilidad consecuente respecto a la ponderación (exigiendo, a lo sumo, un procedimiento de armonización). Ello, puesto que la ponderación implicaría "poner a un derecho sobre otro", cosa de plano excluida por la Constitución y por la propia "naturaleza" de los derechos. Sin embargo, se plantea una pregunta ulterior: ¿de qué derechos y de qué jerarquía hablamos?

Pues bien, hay que dejar claro que en la teoría del derecho no se habla de un solo tipo de jerarquía identificable en los ordenamientos jurídicos. De hecho, hay que diferenciar al menos tres tipos distintos: (1) jerarquías formales, (2) jerarquías materiales, (3) jerarquías axiológicas ${ }^{80}$. El concepto de "jerarquía" es, por supuesto, relacional (es decir que solo se puede definir en virtud de una relación). No hay jerarquías en absoluto, en el vacío: algo o alguien es jerárquicamente superior o inferior respecto de otra cosa o de otra

78 Celano, B. Derecho, justicia, razones. Ensayos 2000-2007. Madrid: Centro de Estudios Políticos y Constitucionales, 2009, 150.

79 Véase, inter alia, SERNA y TOLLER. La interpretación constitucional de los derechos fundamentales, cit.

80 Al respecto, véase Guastini, R. La sintaxis del derecho. Madrid: Marcial Pons, 2016, 207 ss. 
persona. Las jerarquías normativas son, obviamente, jerarquías de "objetos" (las normas), cuya ordenación corresponde a distintos tipos de relaciones.

En el caso de la jerarquía formal, hablamos de una relación entre al menos dos normas en donde la primera (digamos, N1) disciplina la forma de creación de otra (digamos, N2). En el caso de la jerarquía material, la jerarquía tiene que ver con el contenido de las normas. Se dice que en este caso el contenido de una de las dos normas es superior al contenido de la otra. Ahora bien, en el caso de la jerarquía formal nos basta conocer las normas N1 y N2 para saber que la primera es superior a la segunda en la medida en que aquella disciplina la creación de esta; pero esto no sucede en el caso de la jerarquía material: el contenido de dos normas ( 1 y N2) no dice por sí mismo cuál de ellas es superior, de tal suerte que para conocer qué relación jerárquica existe entre ellas necesitamos de una tercera norma (digamos, N3), que prevea dicha ordenación respecto del sistema de las fuentes ${ }^{81}$. Por último, cuando se habla de las jerarquías axiológicas se hace alusión a aquellas que, generalmente en sede judicial, los jueces "componen" -estableciendo diferentes jerarquías entre principios- según sus diferentes valoraciones. Estas, a diferencia de las anteriores, no son jerarquías fijas, sino móviles, justamente porque dependen de la forma en que los jueces "ordenan" los principios en los casos concretos. Nótese bien que esta "movilidad" no depende en absoluto de ningún concepto de esencia o similares, depende enteramente de las valoraciones de los jueces en los casos iusfundamentales. Así, si en un caso C1 un juez decide que el principio P1 (por ejemplo, la libertad de expresión) es más importante o debe prevalecer sobre un principio P2 (por ejemplo, el honor), está componiendo una jerarquía axiológica. Esto, sin embargo, no implica que en un caso $\mathrm{C} 2$ no pueda componer una jerarquía diferente; verbigracia, decidir que en $\mathrm{C} 2$ debe prevalecer el principio P2 y no el principio P1. De allí que se hable de jerarquías móviles ${ }^{82}$.

Pues bien, cuando la Constitución del Ecuador, puesta a examen, dice que todos los derechos y todos los principios son de la misma jerarquía no puede referirse a la jerarquía formal, porque entre estos no hay relación alguna de este tipo (ninguno de estos es conferido -o puede siquiera serlo- por una norma procedimental que discipline la creación de otras). Puede, en cambio, referirse al aspecto material. Empero, esta es una cuestión del todo banal. Que los derechos constitucionales sean de la misma jerarquía material es una obviedad en la medida en que se encuentran en el mismo cuerpo normativo, en la misma escala en el sistema de las fuentes. La Constitución podría no decir nada al respecto, y seguiría siendo del todo pacífico que, en este sentido, todos los derechos constitucionales son de la misma jerarquía. Nada que

81 En el caso ecuatoriano, esto se halla en el artículo 425 de la Constitución de la República.

82 Guastini. La sintaxis del derecho, cit., 207 ss. 
resulte interesante para discutir. Todo esto no supone, sin embargo, que entre los derechos o los principios no se puedan presentar jerarquías axiológicas; es más, esto es parte de una necesaria fenomenología de la ponderación (que, de paso, no corresponde a una "fórmula" determinada, sino a un modelo o mecanismo de razonamiento ${ }^{83}$ ), de una reconstrucción realista. Ponderar principios no puede sino hacerse mediante el establecimiento de prioridades (axiológicas) que permiten resolver los casos de una u otra manera. Esto, por supuesto, en nada afecta a la jerarquía material de los principios o los derechos. Se trata de dos cuestiones que caminan en planos distintos y que merecen niveles de análisis diferentes.

Guastini, Alexy y Barberis concuerdan en esta tesis: las jerarquías axiológicas son móviles, establecidas caso por caso, en concreto, por los jueces. Por ejemplo, dice Barberis: "cada vez que los derechos-razones [principios] son conjuntamente relevantes para un mismo caso, las jerarquías axiológicas pueden mutar; estas no son absolutas, sino simplemente relativas a los casos ya decididos" $"$.

Hay que hacer hincapié en que ponderar no supone estar sujeto a una fórmula definida. Esta es una confusión puramente dogmática. El propio Alexy, con su "fórmula del peso" 85 , pretende, en primer lugar, brindar un instrumento de "racionalización" de las decisiones ponderadas. Los casos que analiza, de hecho, son casos en donde su fórmula no ha sido aplicada (es obvio que esto ha sido así, a menos que alguien quiera caer fácilmente en una falacia post hoc, ergo ante hoc). Pero incluso si se tratase de una fórmula en cuanto tal -cosa muy dudosa-, esta dependería igualmente, pace Alexy, de las valoraciones que hagamos, o de los valores que atribuyamos a los principios; de tal suerte que la celebérrima "fórmula del peso" puede ser usada para obtener un resultado " $p$ " o un resultado " $\neg p)$ no $p$ "; es decir, resultados del todo opuestos. De allí que, en su mayoría, quienes critican la fórmula de Alexy lo hagan porque él realiza asunciones ulteriores que tienen que ver con un tipo -quizás débil- de objetivismo ético (propio de la teoría de los límites externos como suele ser defendida por sus prosélitos), y, también, porque atribuye valores numéricos a valores éticos (cosa que, aunque aquí no se pueda profundizar, es del todo cuestionable $)^{86}$.

83 Celano, B. Derecho, justicia, razones. Ensayos 2000-2007. Madrid: Centro de Estudios Políticos y Constitucionales, 2009, 289.

84 BARBERIS, M. Tres aproximaciones a los derechos fundamentales. Prólogo a MALDONADO MuÑoz, M., Los derechos fundamentales. Un estudio conceptual. Santiago de Chile: Olejnik, 2018,18 .

85 AleXy, R. La fórmula del peso. En CARBonell, M. (ed.), El principio de proporcionalidad y la interpretación constitucional. Quito: Ministerio de Justicia y Derechos Humanos, 2008.

86 Las críticas, de hecho, pueden ser variadas: véase, en general, GuiBourg, R. Alexy y su fórmula del peso. En BeAde, G. y Clérico, L. (eds.), Desafíos a la ponderación. Bogotá: Universidad Externado de Colombia, 2011. 
6. Y, SIN EMBARGO...

Estoy consciente de que lo que he dicho en el acápite anterior puede resultar, en parte al menos, desesperanzador. Pero me gustaría decir algo que podría atenuar, no la descripción dada, que estimo correcta, sino la "desesperanza" que ello puede crear. Esto, dada la forma en que los derechos fundamentales han sido efectivamente recibidos en nuestros ordenamientos y la forma en que se han transformado, a menudo -aunque no siempre- para bien de los ideales de libertad que los inspiraron. Pues bien, el discurso sobre los derechos fundamentales es, originariamente, un discurso moral sobre un sistema moral (no fue sino después de muchos años que estos derechos fueron recogidos en documentos jurídicos ${ }^{87}$ ). Como discurso moral, este presupone ciertos condicionamientos ideológicos que lo configuran (la prohibición del daño para los derechos de libertad, la dignidad del ser humano para los derechos en general, el mantenimiento de la democracia como asociación de hombres libres, etc.). Pragmáticamente, en este sentido, el discurso sobre los derechos fundamentales parecería excluir de plano ciertas posibilidades interpretativas ( $v . g r$. , que pueda incluirse como parte del derecho de propiedad la propiedad de esclavos, el genocidio, la violación como ejercicio de libertad sexual, etc.).

Como discurso ideal sobre la convivencia armónica de seres humanos iguales, dignos y racionales, su aspiración es el establecimiento de un ambiente de fraternidad. No en vano el artículo 1 de la Declaración Universal de los Derechos Humanos dice: "Todos los seres humanos nacen libres e iguales en dignidad y derechos y, dotados como están de razón y conciencia, deben comportarse fraternalmente los unos con los otros". En este orden de cosas, el lenguaje de los derechos (aunque sea en un sentido ideal) aspira a ser un discurso internamente coherente y armónico, de derechos inalienables, irreductibles, inviolables, irrenunciables, indivisibles, etc. Con base en estas asunciones ideales, como se ha visto, algunos teóricos han sostenido que los derechos fundamentales forman "un todo armónico" en donde cada derecho es una parte de esa "sinfonía" 88 . Como sistema moral (por ende, como conjunto más o menos ordenado de principios y reglas), sin embargo, el sistema de los derechos fundamentales parece enfrentarse a dos casos paradójicos: 1) la paradoja de la incompatibilidad entre principios y 2) la paradoja de las excepciones a las reglas ${ }^{89}$.

Dado esto, otros teóricos, menos optimistas (o, mejor, en sentido lato, más realistas), no aspiran a un sistema necesariamente armónico (si bien

87 Maldonado Muñoz, Mauricio. Los derechos fundamentales. Un estudio conceptual. Santiago de Chile: Olejnik, 2018, 25 ss.

88 TOLLER. Los derechos in concert: 'metodologías para tomar decisiones armonizadoras en casos entre derechos y bienes constitucionales', cit.

89 Boвbio, N. Teoría general de la política. Madrid: Trotta, 2009, 447-448. 
no renuncian a que tal pueda considerarse un ideal regulativo), sino que tratan de delinear la forma en que los casos de incompatibilidad deberían ser resueltos, o de identificar las excepciones implícitas en los principios y las reglas, las condiciones de su derrotabilidad, las limitaciones legítimas de los derechos, etc. (casos en los que, de todos modos, frecuentemente están en desacuerdo ${ }^{90}$ ). Pero, como ya he dicho antes, todos estos intentos deben vérselas necesariamente con el fenómeno asociado a la transformación -por obra del derecho- de los problemas sustantivos en problemas procedimentales y de competencia ${ }^{91}$. Se trata del fenómeno de la nomodinámica del derecho: del hecho de que las decisiones adoptadas por autoridades interpretativas determinen, en último término, el significado auténtico de los enunciados jurídicos ${ }^{92}$.

En el ámbito descriptivo de un sistema jurídico, el contenido de los derechos fundamentales puede variar -y efectivamente varía- incluso entre sistemas que comparten, a nivel de principio, ciertos valores o ideales. Las autoridades interpretativas a menudo deben decidir casos supuestamente complejos: si el discurso de odio forma o no parte de la libertad de expresión ${ }^{93}$, si el consumo de marihuana y otras drogas está o no amparado por la privacidad ${ }^{94}$, si el aborto constituye o no un derecho de libertad y en qué $\operatorname{casos}^{95}$, si el matrimonio entre personas del mismo sexo está amparado por los principios de libertad e igualdad ${ }^{96}$, si los padres tienen derecho a negarse a enviar a sus hijos a la escuela oponiendo para ello su cultura y religión ${ }^{97}$, entre otros.

Nos enfrentamos, en realidad, a un discurso que se desarrolla en dos niveles distintos: uno moral y otro jurídico. El propio Guastini dice que en la expresión "derechos fundamentales" podemos hallar al menos dos significados (aparentemente) contrapuestos: un significado de acuerdo con el cual los derechos fundamentales son aquellos que no requieren fundamento en un sistema jurídico, y un significado de acuerdo con el cual los derechos fundamentales son aquellos que fundamentan un sistema jurídico ${ }^{98}$. Estos dos

90 Acerca de los desacuerdos en el derecho, véase LuQue Sánchez, P. y Ratti, G. B. (eds.). Acordes y desacuerdos. Cómo y por qué los jueces discrepan. Madrid: Marcial Pons, 2012.

91 Celano. Derecho, justicia, razones, cit., 23 ss.

92 En el ámbito de la teoría de la interpretación se distinguen dos "objetos jurídicos" diversos: los textos normativos (llamados disposiciones) y el significado de los textos normativos (las normas): véase GuASTINI. Interpretare e argomentare, cit., cap. IV).

93 Véase Brandenburg v. Ohio, 395 U.S. 444 (1969).

94 Véanse Corte Suprema de Justicia de la Nación Argentina, fallos Bazterrica (1986), Montalvo (1990) y Arriola (2009).

95 Véanse Roe v. Wade, 410 U.S. 113 (1973); y Corte Suprema de Justicia de la Nación Argentina: F.A.L. (2012).

96 Véanse Obergeffell v. Hodges, 576 U.S. (2015); y Corte Constitucional del Ecuador: 11-18-CN y 10-18-CN (matrimonio igualitario).

97 Véase Wisconsin v. Yoder, 406 U.S. 205 (1972).

98 Guastini, R. Distinguiendo. Barcelona: Gedisa, 1999, 186. 
significados, en realidad, no están necesariamente divorciados por cuanto en la historia el primero sirvió de base para el reconocimiento de los derechos en el segundo.

Empero, en el primer caso se trata de un sistema normativo moral, de un sistema de normas morales (un sistema, diría Kelsen, estático); mientras que en el segundo se trata de un sistema de normas jurídicas (un sistema, diría Kelsen, dinámico ${ }^{99}$ ). Ambos sujetos a evolución, pero con una estructura diversa. Un sistema normativo es, en palabras de Bobbio, un conjunto estructurado de normas ${ }^{100}$. Y no hay duda de que, en el marco conceptual aquí utilizado, el (sub-)sistema de derechos fundamentales, en el ámbito jurídico, está determinado en su estructura por el ejercicio de las competencias y de los procedimientos tantas veces citados (el fenómeno, repito, de la nomodinámica); ello explica, no tanto los desacuerdos entre juristas acerca del contenido de los derechos, sino más bien las diferencias presentes de sistema a sistema jurídico, de tiempo en tiempo, de acuerdo a una evolución en la que -incluso dadas las mismas disposiciones-podemos encontrar resultados del todo diversos. Un ejemplo por todos: en Argentina, el fallo Bazterrica (1986) despenalizó la tenencia de marihuana para consumo personal (en la medida en que tal conducta está amparada, según ese fallo, por el derecho a la privacidad), aunque su doctrina fue luego abandonada en Montalvo (1990), para ser, no obstante, retomada en Arriola (2009). Todo esto bajo la vigencia del artículo 19 de la Constitución argentina que, según la tradición, protege la intangibilidad de las acciones privadas de las personas. En suma, estando en vigor la misma disposición de la misma Constitución, el derecho a la tenencia de marihuana para consumo personal (amparado por el derecho a la privacidad) es un derecho jurídico ${ }^{101}$ solo conforme a Bazterrica y Arriola. Conforme a Montalvo no lo es. En el primer caso estamos delante de una libertad (el sujeto es libre de consumir marihuana), en el otro estamos delante de una prohibición (el sujeto está obligado a no consumir marihuana, y, si lo hace, está sujeto a una pena) ${ }^{102}$.

99 Kelsen, H. The Law of the United Nations. A Critical Analysis of its Fundamental Problems (1949). New Jersey: The Lawbook Exchange, 2006.

100 Véase, en general, sobre el concepto de sistema normativo en Bobbio, GuAstinI, R. Insiemi strutturati di norme. Contributi di Bobbio alla teoria dei sistemi normativi. En Analisi e diritto, 2004, 103-117.

101 Téngase en cuenta que, como ha señalado Nino, C. S. Sobre los derechos morales. En Doxa. 7, 1990,311-325, aquí no hay redundancia alguna. Véase, también, MALDONADo MuÑoz, MaURICIO. Los derechos fundamentales. Un estudio conceptual. Santiago de Chile: Olejnik, 2018.

102 Piénsese en el caso estadounidense: bajo el amparo de la misma Constitución se han resuelto casos a favor y en contra del mantenimiento de la esclavitud, de la segregación racial, de la prohibición y de la permisión de la anticoncepción, del matrimonio igualitario, del aborto, etc. 
La fórmula del Estado liberal -que dio nacimiento a nuestros modernos Estados democráticos y constitucionales ${ }^{103}$ - según la cual todos somos "dueños de una libertad igual" es nada más que un ideal: un posible punto de llegada y no un punto de partida. La historia de los derechos fundamentales, como lo dejaba claro el mismo Bobbio, no es sino la historia de un proceso de emancipación gradual (todavía hoy incompleto y amenazado) en el que hemos avanzado, aunque el proceso a veces haya resultado tortuoso.

Debemos volver sobre nuestros pasos: todo lo dicho no cambia el hecho de que, en último término, aquello que constituye un derecho en un sistema jurídico depende de los poderes de determinación (interpretativos) que están en juego, y que definen su contenido ${ }^{104}$. Esta es la famosa paradoja de los límites-limitados de la que ya se ha hablado. Una paradoja de la que, como hemos visto, no resulta fácil o posible escapar. Se recordará, además, que ya ha aparecido la cuestión de qué hace que los jueces (sobre todo o exclusivamente los de última instancia) no lleven, en general, su poder a niveles que harían superflua toda noción de derechos fundamentales. Como dije, hay quien se aferra al sistema democrático, al diseño del constitucionalismo, a los vínculos o contraintes que determinarían la actividad interpretativa, a las virtudes judiciales. Probablemente todos sean parte de un rompecabezas hecho de piezas diversas donde seguramente todas las posiciones implicadas tengan una parte de razón. Tengo la impresión, en todo caso, de que esta serie de condicionamientos ideológicos están a su vez definidos, en uno de los sentidos de la palabra ${ }^{105}$, por una "convención". La actividad interpretativa -no solo la jurídica ${ }^{106}$ - es también, al menos en parte, una actividad convencional -lo cual no es incompatible con una forma de realismo moderado- ${ }^{107}$, y aquello que constituye un derecho fundamental (como parte del contenido de un sistema jurídico) depende también del mantenimiento de una serie de convenciones -establecidas en el marco contexto-dependiente de un estado democrático y constitucional-, así como su cambio puede ser el producto de una mutación de la convención (a veces por razones sociológicas, otras por las cambiantes ideologías de la interpretación, entre otros factores $\left.{ }^{108}\right)$. Aunque esto, nótese bien, no determina siempre las decisiones a adoptar. También los intérpretes suelen alejarse de las convenciones interpretativas.

103 Véase Boввіо, N. Liberalismo y democracia. Bogotá: Fondo de Cultura Económica, 2013.

104 Véase Celano. Derecho, justicia, razones, cit., 281 ss.

105 Véase Arena, F. El convencionalismo jurídico. Un recorrido analítico. Madrid: Marcial Pons, 2014.

106 Véase Eco, U. Los límites de la interpretación. Barcelona: Lumen, 1992.

107 Véase, en clave realista moderada, FerRER Beltrán, J. El error judicial y los desacuerdos irrecusables en el derecho. En Luque Sánchez, P. y RATTI, G. B. (eds.), Acordes y desacuerdos. Madrid: Marcial Pons, 2012. Véase nota 4.

108 Véase, en general, TArello, G. L'interpretazione della legge. Milano: Giuffrè, 1980. 
Por ello, incluso cuando se da el caso, sigue siendo cierta la visión de Celano sobre la justicia procedimental en el derecho: en último término, cuál es el contenido del derecho (de un determinado sistema jurídico, se entiende) es una pregunta a la que hemos de responder sobre la base de su contenido efectivo, determinado in fine por las decisiones adoptadas por las autoridades interpretativas, se apeguen o no a una cierta convención interpretativa vigente en una determinada comunidad de intérpretes ${ }^{109}$.

\section{REFERENCIAS}

Aarnio, A. Sobre el contenido de la única respuesta correcta. En Hernández, C. A. y Ortega Gomero, S. (eds.), Hermenéutica y raciocinio jurídico. Bogotá: Universidad Libre, 2012.

Aguiar de Luque, L. Los límites de los derechos fundamentales. En Revista del Centro de Estudios Constitucionales. 14, 1993, 9-34.

Alexy, R. Teoría de los derechos fundamentales. Madrid: Centro de Estudios Constitucionales, 1993.

Alexy, R. La fórmula del peso. En CARBonell, M. (ed.), El principio de proporcionalidad y la interpretación constitucional. Quito: Ministerio de Justicia y Derechos Humanos, 2008.

Arena, F. El convencionalismo jurídico. Un recorrido analítico. Madrid: Marcial Pons, 2014.

BARberis, M. Ferrajoli, o el neoconstitucionalismo no tomado en serio. En Doxa. 34, 2011, 89-93.

Barberis, Mauro. Realismo jurídico continental. En Fabra, J. y Núñez Vaquero, Á. (eds.), Enciclopedia de filosofía y teoría del derecho. Vol. 1. México, D.F.: Unam, 2015.

BARberis, M. Tres aproximaciones a los derechos fundamentales. Prólogo a Maldonado Muñoz, M., Los derechos fundamentales. Un estudio conceptual. Santiago de Chile: Olejnik, 2018.

Bernal Pulido, C. Estructura y límites de la ponderación. En Doxa. 26, 2003, 225-238.

Bernal Pulido, C. La racionalidad de la ponderación. En CArbonell, M. (ed.), El principio de proporcionalidad y la interpretación constitucional. Quito: Ministerio de Justicia y Derechos Humanos, 2008.

Bernal Pulido, C. El derecho de los derechos. Bogotá: Universidad Externado de Colombia, 2008.

Bernal Pulido, Carlos. Une défense de la de la forme de raisonnement juridique du néoconstitutionalisme. Pro manuscripto, 2015.

109 Este tema, en todo caso, merecería ser ulteriormente desarrollado; pero eso es algo que, por razones de espacio y oportunidad, aquí no puedo hacer. 
Boвbio, N. Critica filosofica o condanna politica? En Rivista di Filosofia. 1975, 131-137.

Boввіо, N. La razón en el derecho (observaciones preliminares). En Doxa. 2, 1985, 17-26.

Boвbio, N. El tiempo de los derechos. Madrid: Sistema, 1991.

Boвbio, N. Teoría general de la política. Madrid: Trotta, 2009.

Boвbio, N. Giusnaturalismo e positivismo giuridico. Roma-Bari: Laterza, 2011.

Boвbio, N. Liberalismo y democracia. Bogotá: Fondo de Cultura Económica, 2013.

Bongiovanni, G. Principi come valori o come norme: interpretazione, bilanciamento e giurisdizione costituzionale in Alexy e Habermas. En Ars Interpretandi. 10, 2006, 177-198.

Borowski, M. La estructura de los derechos fundamentales. Bogotá: Universidad Externado de Colombia, 2003.

Bulygin, E. Sobre el status ontológico de los derechos humanos. En Doxa. 4, 1987, 79-84.

Caracciolo, R. Realismo moral vs. positivismo jurídico. En Comanducci, P. y Guastini, R. (eds.). Analisi e diritto 2000. Torino: Giappichelli, 2001, 37-44.

CARTABIA, M. I principi di ragionevolezza e proporzionalità nella giurisprudenza costituzionale italiana. En Conferenza trilaterale delle Corti costituzionali italiana, portoghese e spagnola. Roma: Palazzo della Consulta, 2013.

CAstillo Córdova, L. F. ¿Existen los llamados conflictos entre derechos fundamentales? En Cuestiones Constitucionales. 12, 2005, 99-129.

Celano, B. Derecho, justicia, razones. Ensayos 2000-2007. Madrid: Centro de Estudios Políticos y Constitucionales, 2009.

Chiassoni, P. Técnicas de interpretación jurídica. Breviario para juristas. Madrid: Marcial Pons, 2011.

Cianciardo, J. Los límites de los derechos. En Dikaion. 10, 2001, 53-73.

Cianciardo, J. El ejercicio regular de los derechos: análisis y crítica del conflictivismo. Buenos Aires: Ad-Hoc, 2007.

Cianciardo, J. El principio de razonabilidad. Del debido proceso sustantivo al moderno juicio de proporcionalidad. Buenos Aires: Ábaco, 2009.

CLÉRICO, L. El examen de proporcionalidad: entre el exceso por acción y la insuficiencia por omisión o defecto. En CARBONELL, M. (ed.), El principio de proporcionalidad y la interpretación constitucional. Quito: Ministerio de Justicia y Derechos Humanos, 2008.

Comanducci, P. Principios jurídicos e indeterminación del derecho. En Doxa. 21 (II), 1998, 89-104.

Comanducci, P. Problemi di compatibilità tra diritti fondamentali. En Analisi e diritto. 2002-2003, 317-329. 
Cотта, S. La coexistencialidad ontológica como fundamento del derecho. En Persona y Derecho. 9, 1982, 13-18.

Eco, U. Los límites de la interpretación. Barcelona: Lumen, 1992.

Ferrajoli, L. Dei diritti e delle garanzie. Conversazione con Mauro Barberis. Bologna: Il Mulino, 2013.

FerRer Beltrán, J. El error judicial y los desacuerdos irrecusables en el derecho. En LuQue Sánchez, P. y Ratti, G. B. (eds.), Acordes y desacuerdos. Madrid: Marcial Pons, 2012.

GiAnFORMAGgio, L. La noción de procedimiento en la teoría de la argumentación jurídica. En Doxa. 14, 1993, 159-167.

Giardelli, L. El derecho a la igualdad y el sistema de escrutinios. Pro manuscripto, 2006.

Gorra, D. Crítica a la teoría de la argumentación jurídica de Robert Alexy: sistema de ponderación de principios. En Nuevas Fronteras de Filosofía Práctica. 3, 2014, 43-61.

Guastini, R. Distinguiendo. Barcelona: Gedisa, 1999.

Guastini, R. Insiemi strutturati di norme. Contributi di Bobbio alla teoria dei sistemi normativi. En Analisi e diritto, 2004, 103-117.

Guastini, R. Interpretare e argomentare. Milano: Giuffrè, 2011.

Guastini, R. Distinguendo ancora. Madrid: Marcial Pons, 2013.

Guastini, R. Interpretación y construcción jurídica. En Isonomía. 43, 2015, 11-48.

Guastini, R. La sintaxis del derecho. Madrid: Marcial Pons, 2016.

Guibourg, R. Alexy y su fórmula del peso. En Beade, G. y Clérico, L. (eds.), Desafíos a la ponderación. Bogotá: Universidad Externado de Colombia, 2011.

HÄberle, P. La garantía del contenido esencial de los derechos fundamentales en la Ley Fundamental de Bonn. Madrid: Dykinson, 2003.

Kant, I. The Metaphysics of Morals (1797). New York: Cambridge University Press, 1991.

Kelsen, H. The Law of the United Nations. A Critical Analysis of its Fundamental Problems (1949). New Jersey: The Lawbook Exchange, 2006.

LinARes, J. Razonabilidad de las leyes. Buenos Aires: Astrea, 2010.

LuQue SÁnchez, P. La concepción irenista de la constitución. Sobre la posibilidad de una reconstrucción armónica del contenido ético-sustantivo del Estado constitucional. En Isonomía. 38, 2013, 35-65.

Luque Sánchez, P. y Ratti, G. B. (eds.). Acordes y desacuerdos. Cómo y por qué los jueces discrepan. Madrid: Marcial Pons, 2012.

Luther, J. Ragionevolezza e dignità umana. En Polis Working Papers, 591. Tribunale di Alessandria, Università del Piemonte Orientale, Working Paper n. 79, 2006. 
Maldonado Muñoz, M. Conflictivismo y anti-conflictivismo en los derechos fundamentales. En Diritto \& questioni pubbliche. 16, 2, 2016, 105-131.

Maldonado Muñoz, M. Los derechos fundamentales. Un estudio conceptual. Santiago de Chile: Olejnik, 2018.

Maldonado Muñoz, M. Principi, diritti fondamentali e teoria degli insiemi. En Materiali per una storia della cultura giuridica. XLIX (2), 2019, 535-556.

Maldonado Muñoz, M. El realismo jurídico (apuntes para una introducción). En Iuris Dictio. 25, 2020, 13-25.

Martínez-Pujalte, A. L. La garantía del contenido esencial de los derechos fundamentales. Madrid: Centro de Estudios Constitucionales, 1997.

Marx, K. El 18 Brumario de Luis Bonaparte (1851-1852). Madrid: Fundación F. Engels, 2003.

Mercader Uguina, J. Tutela judicial efectiva, control de razonabilidad de las decisiones judiciales y "canon reforzado" de motivación en la doctrina del Tribunal Constitucional. En Revista del Ministerio de Trabajo y Asuntos Sociales. 73, 2008, 127-146.

Michael, L. ¿El contenido esencial como denominador común de los derechos fundamentales en Europa? En ReDCE. 6 (11), 2009, 165-187.

Moreso, J. J. Alexy y la aritmética de la ponderación. En CARbonell, M. (ed.), El principio de proporcionalidad y la interpretación constitucional. Quito: Ministerio de Justicia y Derechos Humanos, 2008.

Nino, C. S. Sobre los derechos morales. En Doxa. 7, 1990, 311-325.

Nino, C. S. Fundamentos de derecho constitucional. Buenos Aires: Astrea, 2005.

OrRego SÁNCHEZ, C. Supuestos conflictos entre derechos humanos y la especificación de la acción moral. En Revista Chilena de Derecho. 37 (2), 2010, 311-342.

ORUNESU, C. Los conflictos entre derechos y el derecho internacional en la jurisprudencia de la CSJN. Pro manuscripto, 2014.

Pino, G. Conflictos entre derechos fundamentales. Una crítica a Luigi Ferrajoli. En Doxa. 32, 2009, 649-650.

Pintore, A. Democrazia e diritti. Sette studi analitici. Pisa: ets, 2010.

Prieto Sanchís, L. El juicio de ponderación constitucional. En Carbonell, M. (ed.), El principio de proporcionalidad y la interpretación constitucional. Quito: Ministerio de Justicia y Derechos Humanos, 2009.

Ross, W. D. The Right and the Good (1930). Oxford: Clarendon Press, 2002.

Ruiz Manero, J. Due problemi per la ponderazione: tensioni irrisolvibili e principi imponderabili. En Luque Sánchez, P. y Scamardella, F. (eds.), Gli argomenti del costituzionalismo: la tensione tra etica e diritto. Napoli: Editoriale Scientifica, 2014. 
SAPAG, M. El principio de proporcionalidad y de razonabilidad como límite constitucional al poder del Estado: un estudio comparado. En Dikaion, 17, 2008, 157-198.

Searle, J. Prima facie obligations. En Raz, J. (ed.), Practical Reasoning. Oxford: Oxford University Press, 1978.

SERnA, P. Derechos fundamentales: el mito de los conflictos. Reflexiones teóricas a partir de un supuesto jurisprudencial sobre intimidad e información. En Humana Iura. 4, 1994, 197-234.

Serna, P. y Toller, F. La interpretación constitucional de los derechos fundamentales. Una alternativa a los conflictos de derechos. Buenos Aires: La Ley, 2000.

TARello, G. L'interpretazione della legge. Milano: Giuffrè, 1980.

Thomson, J. J. Self-defense and rights. En The Lindley Lecture. The University of Kansas, 1976.

Thomson, J. J. Some ruminations on rights. En Ariz. L. Rev. 19 (45), 1977, 46-60.

TolLER, F. La resolución de los conflictos entre derechos fundamentales. Una metodología de interpretación constitucional alternativa a la jerarquización y al balancing test. En Ferrer Mac-Gregor, E. (ed.), Interpretación constitucional. T. II. México, D.F., Porrúa, 2005.

TOller, F. Los derechos in concert: 'metodologías para tomar decisiones armonizadoras en casos entre derechos y bienes constitucionales'. En Cianciardo, J. (ed.), Constitución, neoconstitucionalismo y derechos: teoría y aplicaciones en la interpretación de los derechos constitucionales. México, D.F.: Porrúa, 2012.

TROPER, M. Una teoria realista dell'interpretazione. En Materiali per una storia della cultura giuridica. XXIX (2), 1999, 473-493.

Zagrebelsky, G. El derecho dúctil: ley, derechos, justicia. Madrid: Trotta, 2011. 